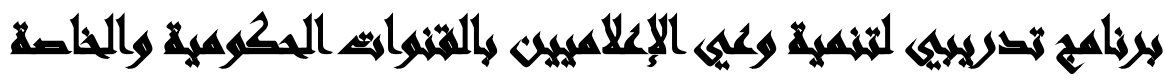

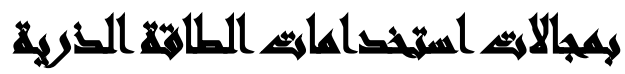

[10]

طارق عبد العزيز فرج(')- محمد معوض ابراهيم(؟)- عبد الحكيم عبد الرحمن المنهاوي(ז)

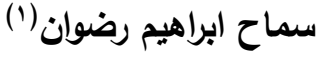

( ) هيئة الطاقة الذرية بالقاهرة r) كلية الدراسات العليا للطفولة، جامعة عين شمس r) الكلية الفنية العسكرية

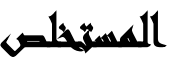

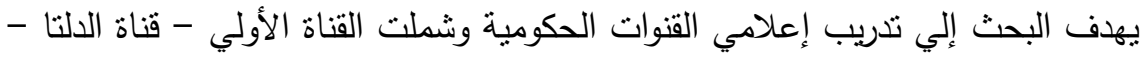

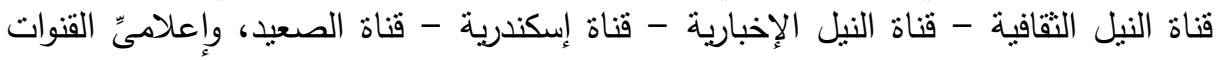

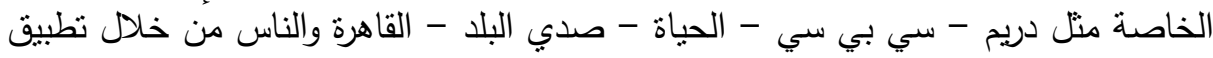

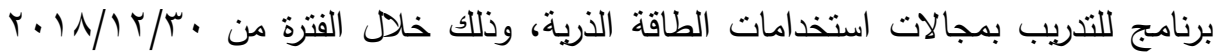

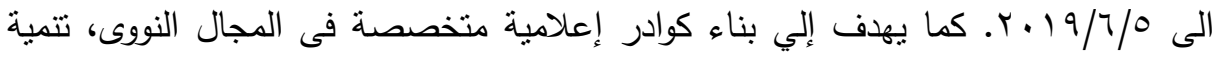

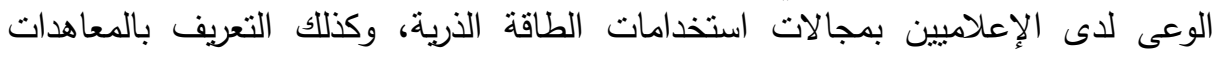

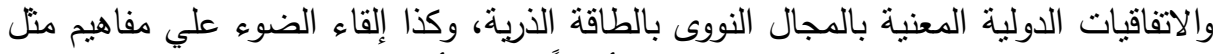

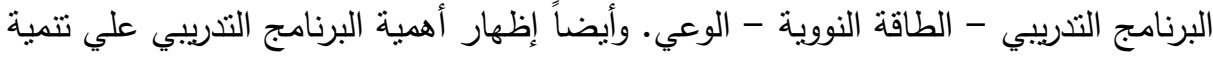

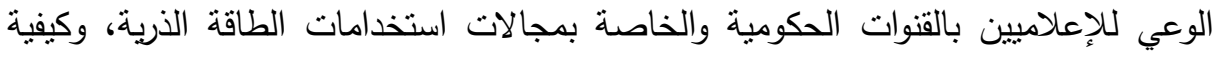

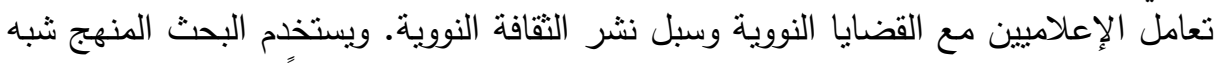

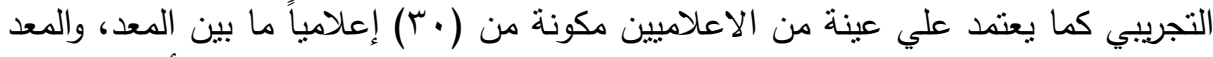

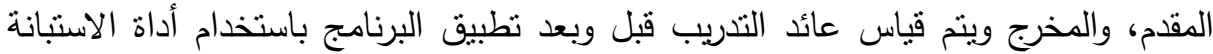

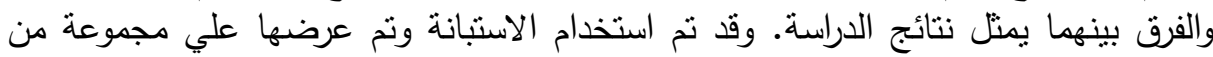

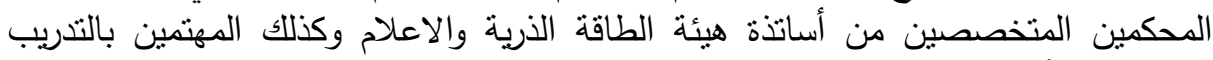
الاعلامي للتأكد من صلاحيتها للتطبيق.

وكانت أهم النتائج هي: أوضح معامل الثبات لأداة جمع البيانات لأسئلة قائمة الاستبيان

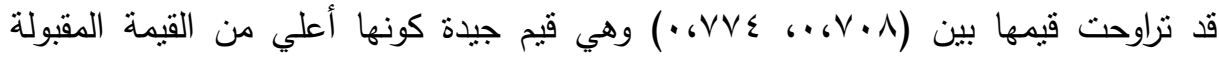

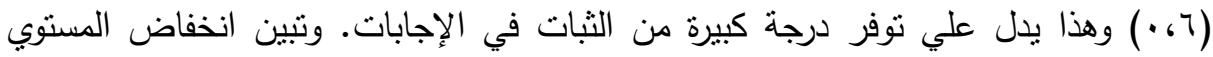

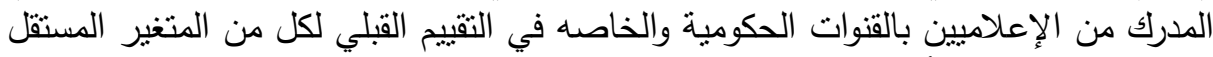
(تدريب الإعلاميين) وأبعاده الثناثة (المنهج، المدربين، الأدوات المساعداعدة). 


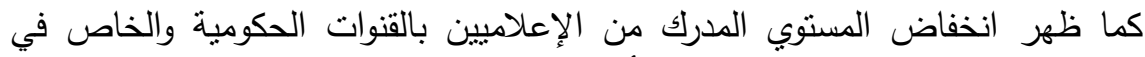

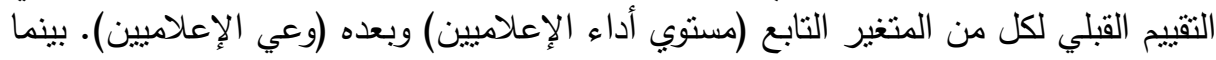

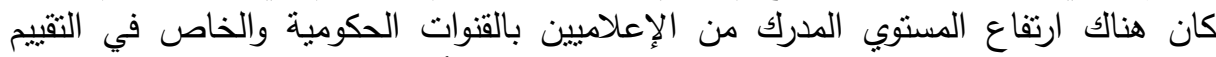

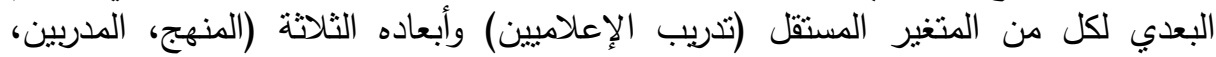

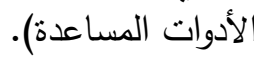

وهذا يؤكد عدم صحة الفرض القائل: توجد علاقة ذات دلالة الحصائية بين البرنامج

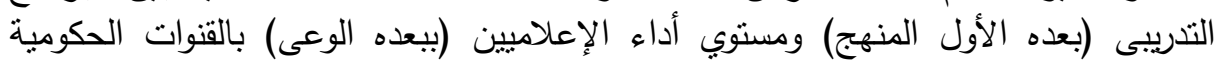

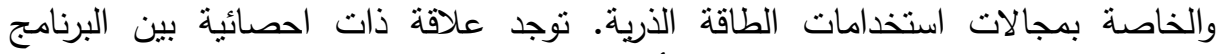

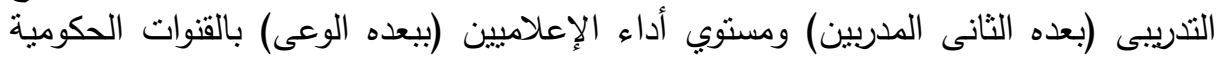

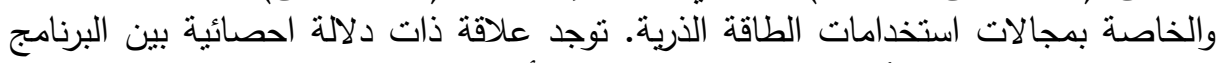

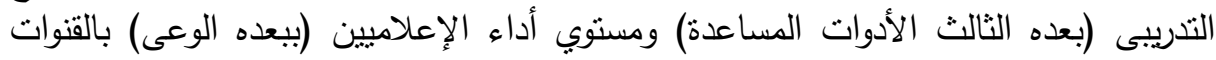

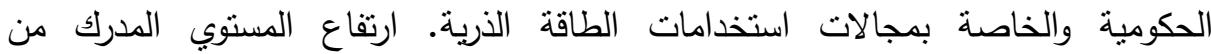

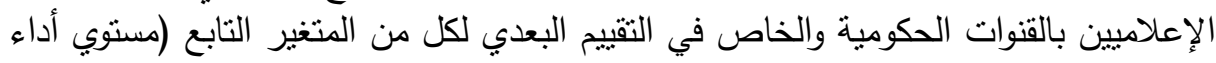
الإعلاميين) وبعد (وعي الإعلاميين).

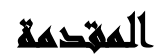

تتنهـ مجتمعاتتا العربية جدلاً دائراً حول الطاقة النووية وضرورتها من عدمها للوطن العربي، وكذلك قضايا الأمان النووي التي برزت بشكل واضح بعد حادثة تشرنوبيل. وإذا أضفنا

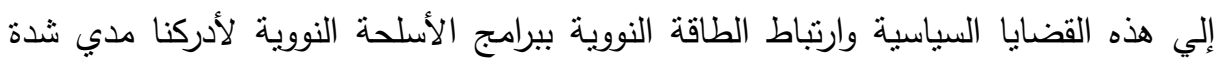

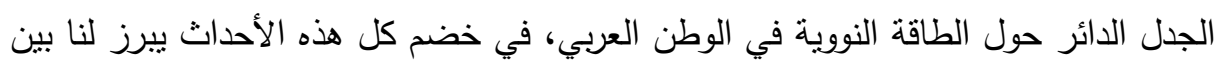

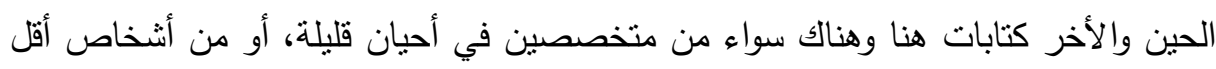
ما يمكن وصفهم به هو عدم الموضوعية في التتاول واستغلال مشاعر الجماهير في أحيان

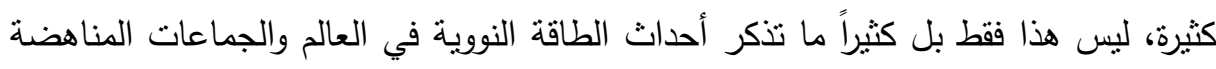

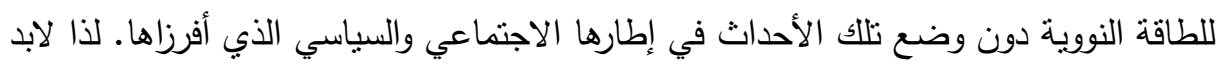

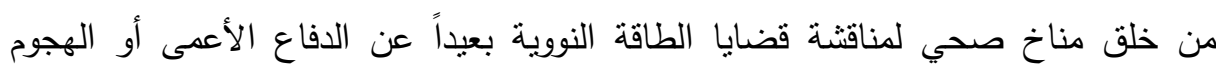

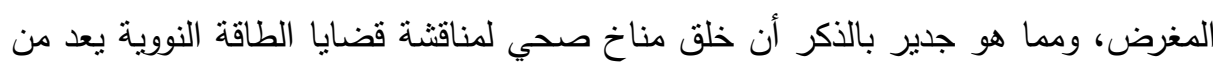

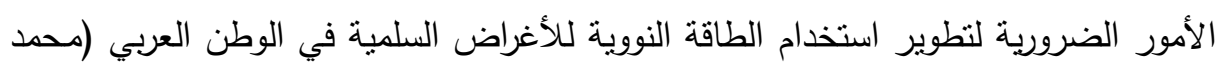
حسن محمد، الهيئة العربية للطاقة الذرية العدد الثاني، 997 (1). 
سيقوم الباحث بمسح الدراسات السابقة للاستشراف للإجراءات التي يقوم بها وتحديد كثير من الجوانب المنهجية كمكلة البحث وغيرها. كما تعتمد علي الركيزة الثانية وهي الدراسة الإسنطلاعية والتي من أهم وظائفها أن يقوم الباحث في دراسته علي رؤية قد استشفها من دراسته الإستطلاعية.

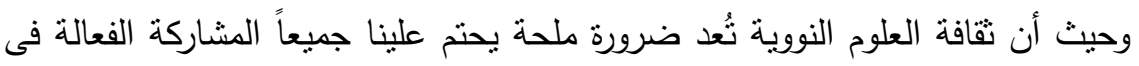
نشرها والتدقيق فى مفرداتها، وإيماناً منا بضرورة إعداد منظومة منكاملة يمكنها التفاعل مع صعابه مجموعات العصر الحديث والتعرف على كل ما هو جديد فى مجال العلوم والتكنولوجيا فى

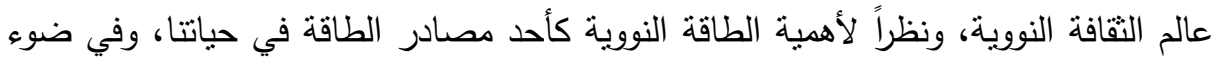

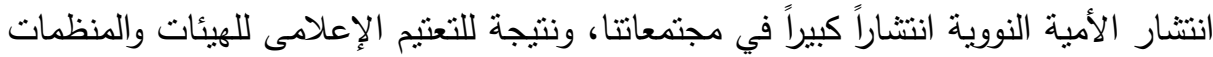
النووية العالمية، وكنللك عدم توفر الثقافة النووية في الطبقة المنقفة وبالأخص الإعلاميين الذين لم يتوفر لديهم القدر الكافِ من هذه المعلومات فى حين أنهم يمثلون القاعدة الرئيسية

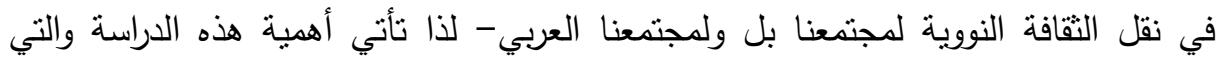
تهدف إلي زيادة المعرفة لاي الإعلاميين بشئون الطاقة النووية، ولاسيما بعد تحقيق الحلم

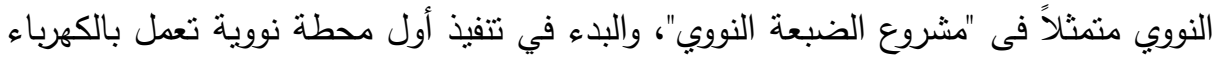
للحصول علي الطاقة النووية، وإيماناً منا بانطلاق الحوار المجتمعي حول هذا لهاء المشروع القومي، ولتحقيق المعادلة الصعبة بمراعاة مصلحة بلدنا الحبيية مصر ، وبالتالي المواطن من

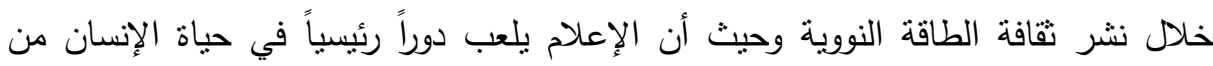

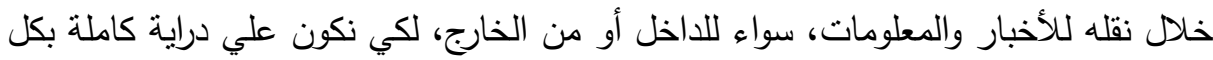

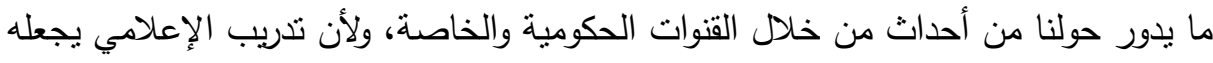

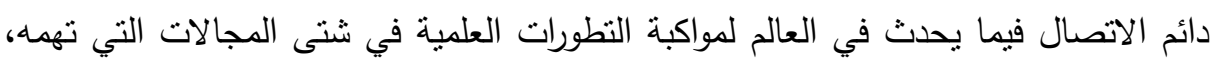
وتساعده في تطوير نفسه في الحقل الذي يعمل فيه، الأمر الذي يتطلب تصميم برنامج تدريبي للإعلاميين لتعريفهر باستخدامات الطاقة الذرية وبالتالي تحسين كفاءتهم من خلال فياس الوعي. 
وما يمنته الإعلام - كمنظومة اتصال محورية وفاعلة - في حباة المواطن لما له من أهمية قصوي في نقل الأحداث سواء محلياً أو عالمياً من خلال القنوات الحكومية والقنوات

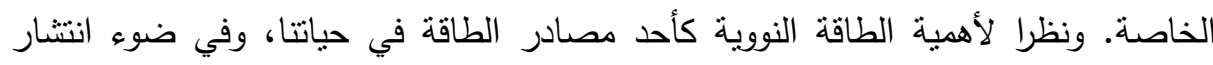
الأمية النووية انتشاراً كبيراً بين المواطنين المصريين وكذللك العرب، ونتيجة للتعتيم الإعلامى فئه

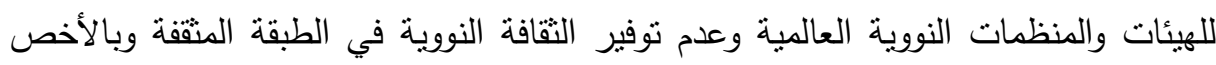
الإعلاميين - المسئولين عن نقل المعلومات. يتضح من ذلك ضرورة نشر الثقافة النووية في

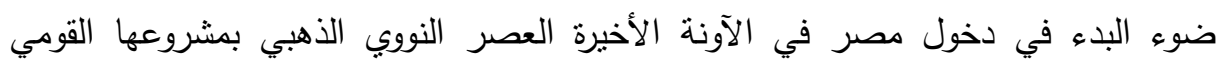

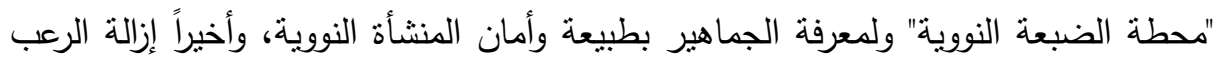
من مصطلح الطاقة النووية بين المواطنين.

ومن هذا المنطلق جاء البحث ليقدم برنامج تدريبي للاعلاميين بالقنوات الحكومية لئن

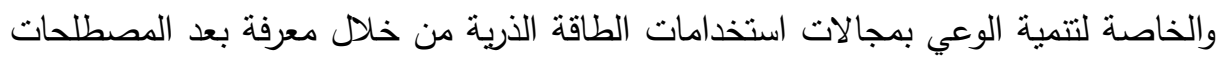
النووية وكذلك المعاهدات والإتفاقيات الدولية لتتاول مثل هذه الثقافة. (مجلة اخبار الطاقة الذرية، ع ( • r م، يوليو، العدد السادس).

وطبق البرنامج التدريبي علي اعلامي القنوات الحكومية منل القناة الأولي - قناة الدلتا لتأل

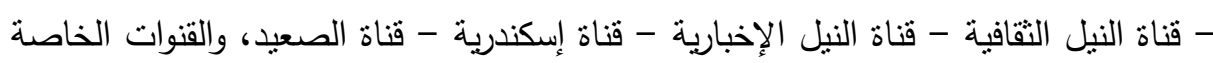
منل دريم - سي بي سي - الحياة - صدي البلد - القاهرة والناس.

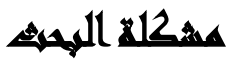

تعتبر الدراسات السابقة والدراسات الإستطلاعية ركيزتين رئيسيتين لهذا البحث. وحيث

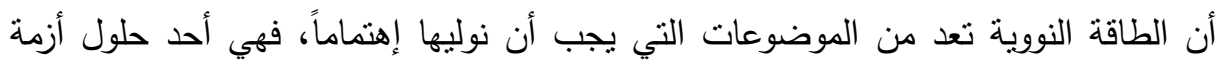

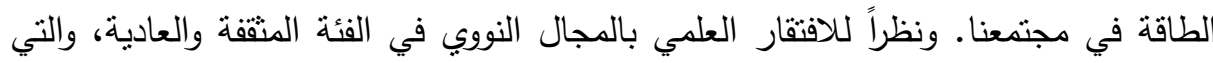
يجب أن تكون علي دراية كاملة ووعي بأحداث ونطورات الطاقة النووية خاصة بعد تبلور المشكله عقب واقعة ميت نما بالقليوبية.

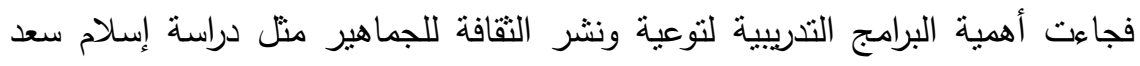

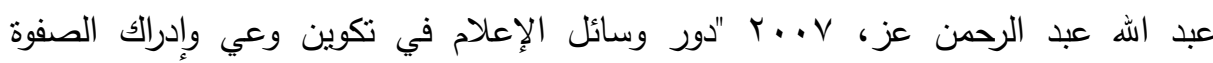


المصرية تجاه القضايا النووية". حيث هدفت هذه الدراسة إلى معرفة طبيعة إدراك الصفوة

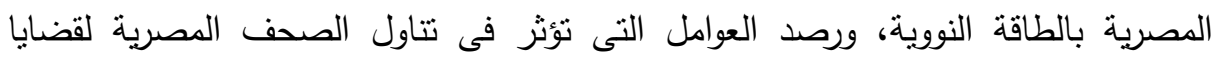
الطاقة النووية وكذا النعرف علي تأثير للمضمون الإخباري لوسائل الإعلام علي إدراك الصفورة

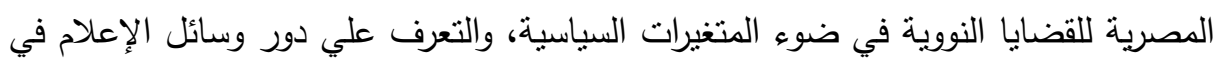
نشر الثقافة النووية بين الصفوة المصرية. وقد خرجت الدراسة بتوصيات أهمها ضرورة زيادة الوعي بالجوانب الإيجابية عن استخدامات الطاقة، وضرورة إطلاق حوار عربي حول الطاقة

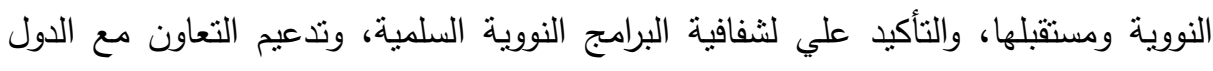

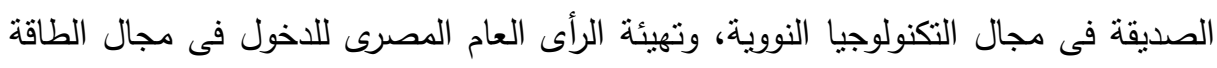

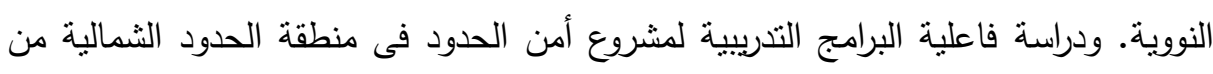

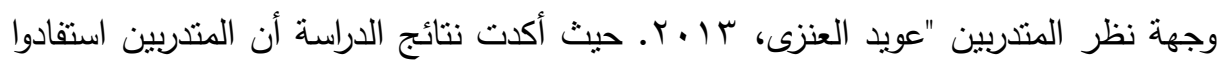

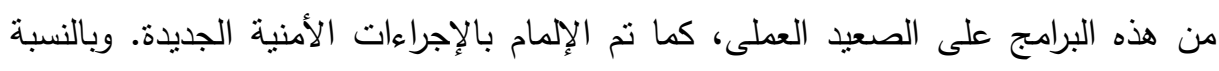

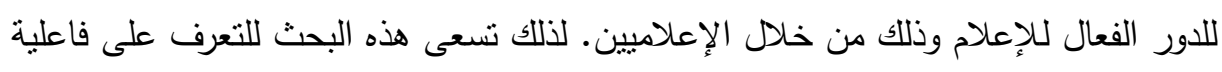
برنامج تدريبي لزيادة وعي الإعلاميين بالقنوات الحكومية والخاصة بمجالات استخدامات الإهي

الطاقة الذرية.

\section{أسهيلا المهشه}

• ما دور التدريب في تتمية وعي الإعلاميين بمجالات استخدامات الطاقة الذرية؟ ماتج

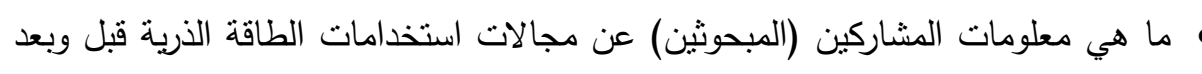

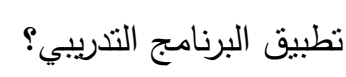

• ما إمكانية إعداد برنامج تدريبي للإعلاميين بمجالات استخدامات الطاقة الذرية؟

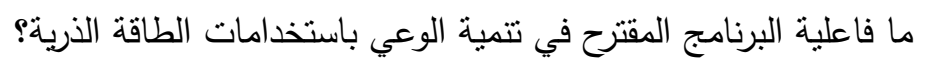




\section{أهفاهذ المهيث}

تتمية الوعي باستخدامات الطاقة الذرية للإعلاميين من خلال تعرضهم للبرنامج المقترح. رصد إهتمامات الإعلاميين بمجالات استخدامات الطاقة الذربة قبل وبعد نطبيق البرنامج التدريبي. تعريف المشاركين في البرنامج بالمفاهيم المطلوبة لاستخدام الطاقة الذرية في المجالات المختلفة.

\section{أهمية المهبه}

الناحية النظرية: الأهمية الكامنة في إثراء المكتبات بهذه النوعية من الأبحاث، نظرا لندرة وأهمية نشر الثقافة النووية، مع نوفير دراسة ميدانية على أساس منهجى، نتتاول كيفية فهم

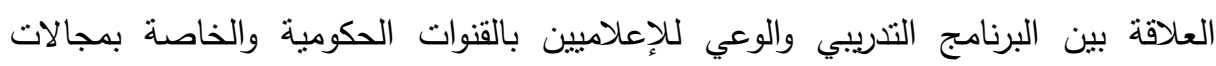
استخدامات الطاقة الذرية. الناحية العملية: تتبع الأهمية العملية لموضوع البحث من خلال نوعية الجمهور بالثقافة النووية، نظراً للبدء في خطوات المشروع القومي النووي (الضبعة) ومن ثم الإعلاميين، ويشمل ذلك ما يلي: • كيفية التعامل الآمن لإعلامي القنوات الحكومية والخاصة فى حالة حدوث كوارث نووية أو إثعاعية، ونقلها للمواطن بصورة بسيطة وسهلة يستوعبها رجل الثنارع العادى وتعريف

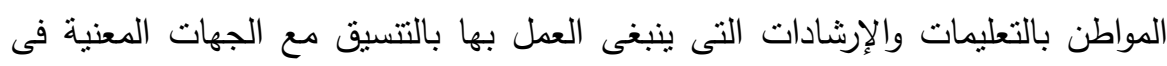
هذا الصدد. • نقل المعلومات النووية للإعلاميين بالقنوات الحكومية والخاصة والمعنية بتأمين البيئة

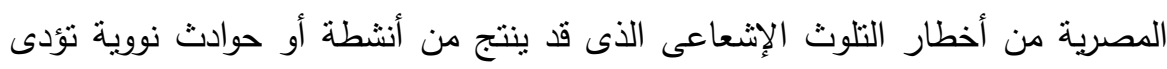

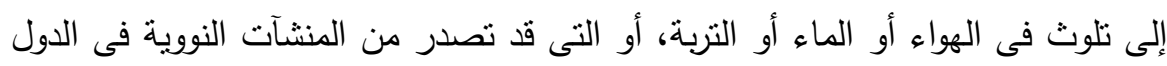

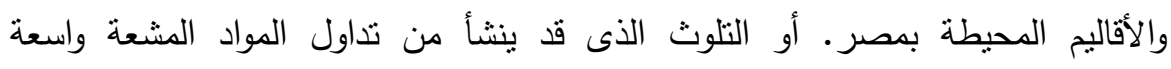
الاستخدام فى مصر ، وذلك بالتسيق مع هيئة الطاقة الذرية المصرية صاحبة المعلومات الأولى والرئيسية فى هذا المجال. 


\section{هغخ المهيد}

توجد فروق ذات دلالة إحصائية في الدرجات التي يحصل عليها الإعلاميون في الوعي باستخدامات الطاقة الذرية قبل وبعد تعرضهم للبرنامج المقترح لصالح التطبيق البعدي.

\section{همطلحمايت الهمبه}

البرنامج التدريبي: وهو عبارة عن خطة تتضمن بشكل رئيسي مجموعة من الأهداف التدريبية المختارة في ضوء تحليل العمل المحتوى وطرق التدريب والوسائل المساعدة التي ينت من خلالها تحقيق تلكك الأهداف، إضافة إلى أدوات التقويم اللازمة للتأكد من تحقيق البرنامج

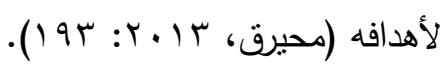

الإعلام: هو تزويد الجماهير بالأخبار الصحيحة، والمعلومات السليمة، والحقائق الثابتة التي

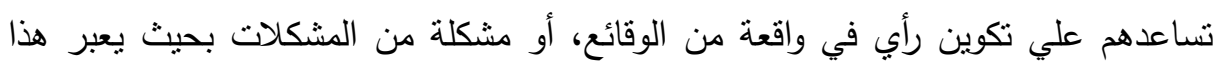

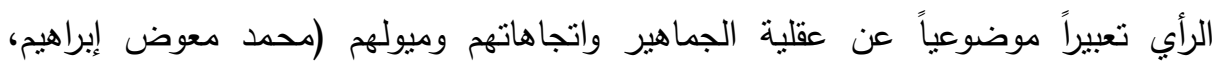
(1) : r.. r

الإعلاميين: فريق من الإعلاميين في تخصصات مختلفة كمد البرنامج أو كمقدم أو كمرج

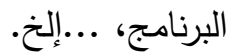

الوعي: هو إدراك الفرد لنفسه والبيئة المحيطة، فهو حصاد إدراك الناس وتصوراتهم للعالم المحيط بهم بما اشتمل عليه من علاقات بالطبيعة والإنسان وهو إدراك تصور يحدد بحالة

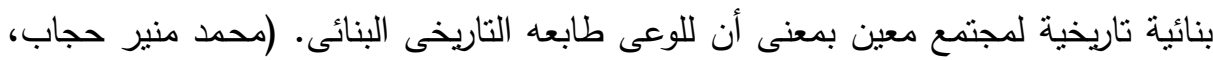
. (Y797، Y.. مجالات استخدامات الطاقة الأرية: هناك العديد من الإستخدامات السلمية للطاقة الذرية تسهم في تتمية المجتمع منل مجالات (الطب، الزراعة، الصناعة، البيئة،.......). 


\section{التراسايت الساريه}

تتاول الباحثون في هذه البحث على عدد من الدراسات متعلقة بتتمية وعي الإعلاميين بالقنوات الحكومية والخاصة بمجالات استخدامات الطاقة الذرية ومهارات تتاولها من تحقيق الأهداف، من حيث علاقتها بالمتغيرات وأهم النتائج والتوصيات. وقد تم عرض هذه الدهات الدراسات وفقاً للتدرج التاريخي من الأحدث إلي الأقدم وفيما يلي ملخص الهان لهذه الدراسات. دراسة (Al-Mzary et al, 2015): أثز التدريب علي أداء العاملين ومن وجه نظرهم دراسة حالة جامعة اليرموك. هدفت البحث إلى معرفة مواقف القيادات الإدارية والموظفين الإداريين من الدورات التدريبية المقدمة، ومعرفة أثز التدريب علي أداء العاملين في جامعة اليرموك بالأردن. وخرجت البحث بنتائج أهمها أن هناك علاقة بين التنريب الفعال وأداء الموظفين. واستفاد الباحث منها في أن التدريب له أثز علي تحسين أداء المتدربين.

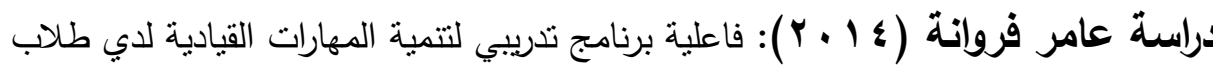

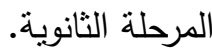

هدفت البحث إلى الكثف عن فاعلية برنامج تدريبي لتتمية المهارات القيادية لدى طلبة

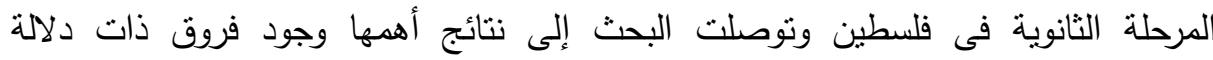

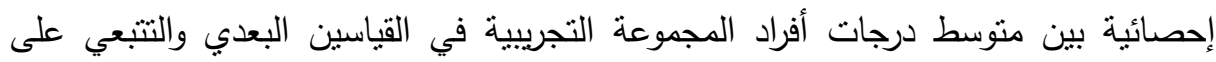
مقياس المهارات القيادية بعد مرور • 7 يوماً من تطبيق البرنامج التدريبي. وقد استقاد الباحث

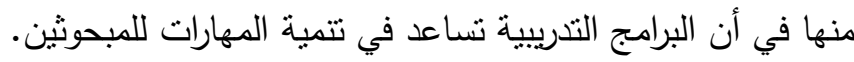
دراسة هبه دغمش ( ( ا ب Y): فاعلية برنامج تدريبي في تتمية مهارات تصميم وإنتاج

ملف الإنجاز الإلكتروني والاتجاه نحوه لدي طالبات كلية التربية بالجامعة الإسلامية بغزة. هدفت البحث إلي بناء برنامج تدريبي في تتمية مهارات تصميم وإنتاج ملف الإنجاز الإلكتروني والاتجاه نحوه لاى طالبات كلية التربية بالجامعة الإسلامية بغزة، واستخدت

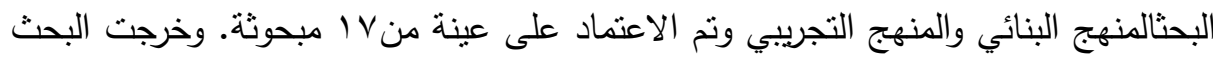
بنتائج أهمها فاعلية البرنامج التدريبي في تتمية مهارات تصميم وإنتاج ملف الإنجاز 
الإلكتروني لمدة الزمنية الكافية له. وقد استفاد الباحث بالتأكيد علي فاعلية البرنامج التدريبي في تتمية المهارات للمشاركين.

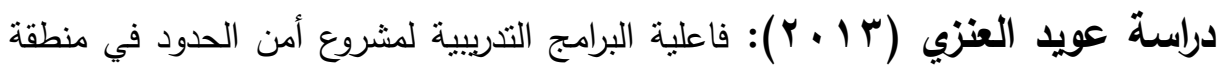
الحدود الثمالية من وجهة نظر المتدربين. هدفت البحث لمعرفة أهداف البرامج التدريبية في تحقيق أهداف مشروع أمن الحدود بمنطقة الحدود الثمالية بالمملكة العربية السعودية، ونم استخدام أسلوب العينة العشوائية فى الهى البحث والمنهج الوصفى التحليلى. وأكدت نتائج البحث أن المتدربين استفادوا من هذه البرامج البها

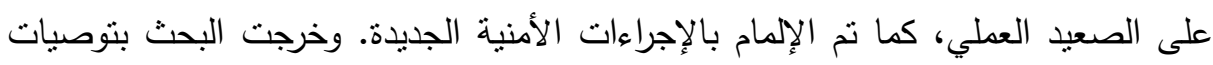
أهمها ضرورة تتوع أساليب التدريب بشكل يتتاسب مع قدرات المندربين. مما يؤكد للباحث أهمية البرامج التدريبية في تتمية قدرات المتدربين.

دراسة جلال رومية (Y Y Y Y): فاعلية برنامج تدريبي مقترح في ضوء معايير الجودة الشاملة في تحسين آداء معلمي الرياضيات في المرحلة الأساسية الدنيا بغزة. الدراسة هدفت إلى معرفة فاعلية برنامج تدريبي مقترح في تحسين آداء المعلمين

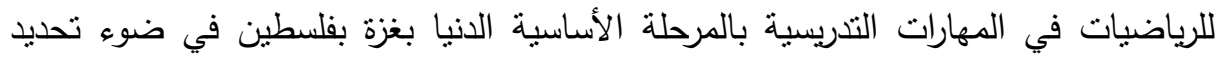

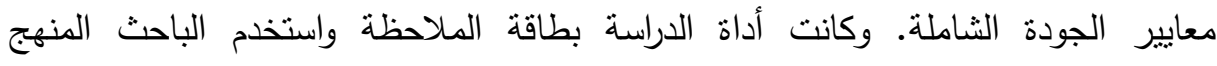
التجريبى. وقد أظهرت نتائج الدراسة وجود فروق ذات دلالة إحصائية عند مستوى دلالة (0.05) بين متوسط درجات معلمي ومعلمات المجموعة التجريبية في النطبيق القبلي وأيضاً البعدي لبطاقة الملاحظة لصالح النطبيق البعدي، وذللك من خلال فاعلية البرنامج التدريبي في تتمية تحسين الآداء التدريسي للمعلمين والمعلمات عينة الدراسة. دراسة طلعت عيسي (11 ( Y): فاعلية استخدام وسائل الإعلام الجديد في نجاح فعاليات إنهاء الانقسام الفلسطيني. هدفت هذه البحث إلي التعرف إلى خصائص نشطاء المجتمع الفلسطيني الذين استخدموا وسائل الإعلام الجديدة في الدعوة إلى فعاليات إنهاء الانقسام الفلسطيني، من خلاه 
مواقع التواصل الاجتماعي، وتم استخدام الاستبيان كأداه للدراسة عن طريق منهج المسح

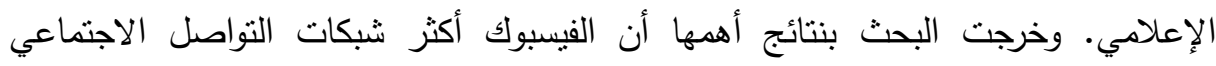

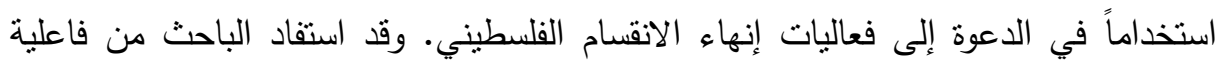

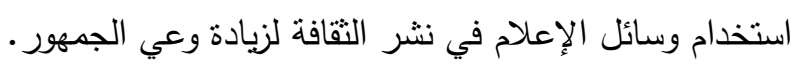

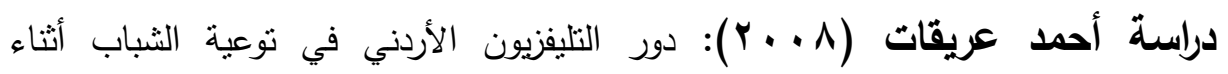

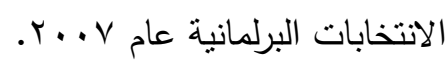
هدفت الدراسة إلي معرفة الدور الذي يقوم به التليفزيون الأردني في توعية الثباب أثثاء

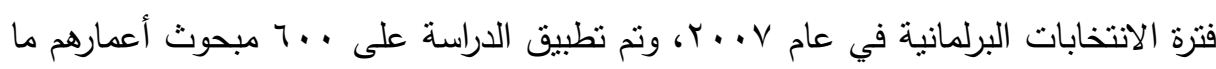

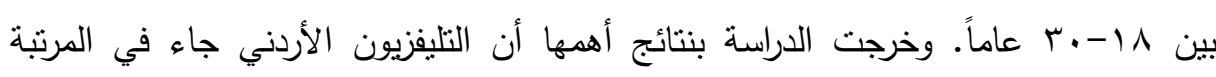
السابعة من الوسائل الاتصالية التي تعرض لها الثباب أنثاء الثراء الحملة الإعلامية.

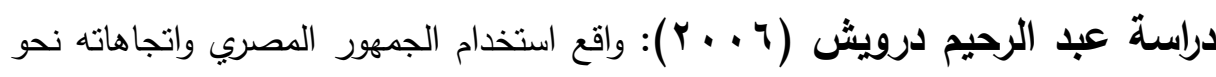
التليفزبون.

هدفت الدراسة إلي التعرف علي اتجاهات الجمهور نحو التليفزيون المصري الرسمى

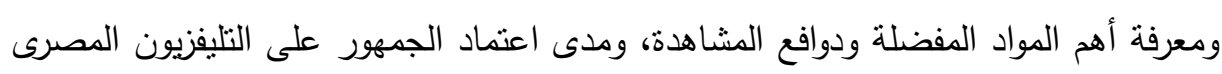

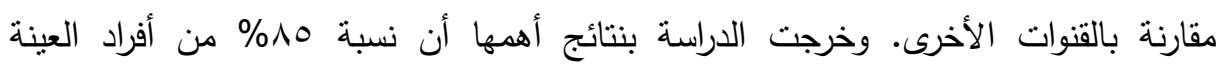

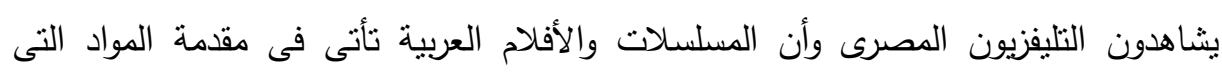
يفضل المبحوثين مشاهدتها، وأن مشاهدة القنوات الفضائية أثرت على مشاهدة التليفزيون

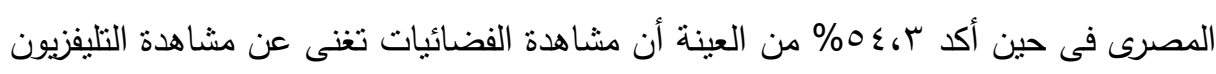

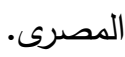

\section{الإطار اللهظريه للتواسمة}

نظرا للنطور التكنولوجي والعلمي السريع وما يصاحبه من مفردات علمية جديدة ونتيجة

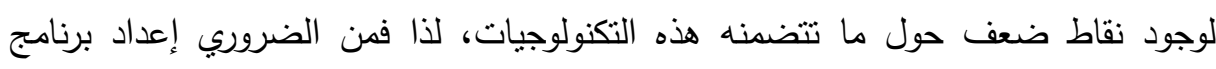

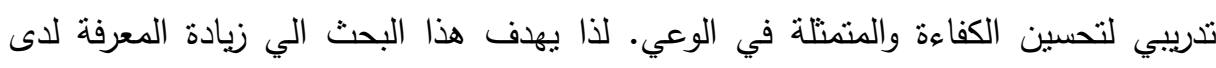


الإعلاميين بشئون الطاقة النووية من خلال التأكيد علي دور كل من الإعلام والبرنامج التنريبي في تحسين مستوي أداء الإعلاميين بمجالات استخدامات الطاقة الذرية.

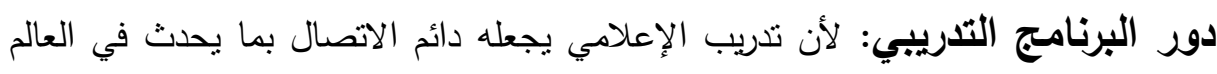

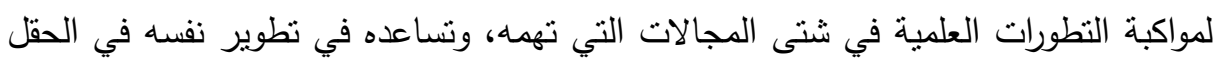

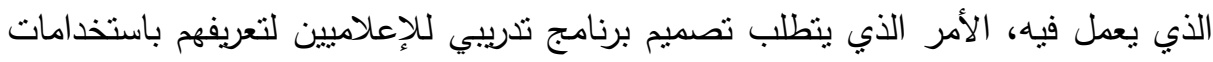

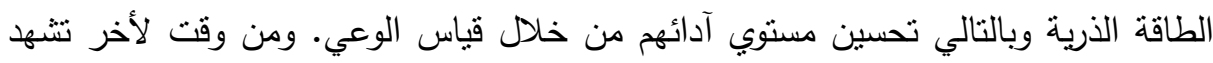

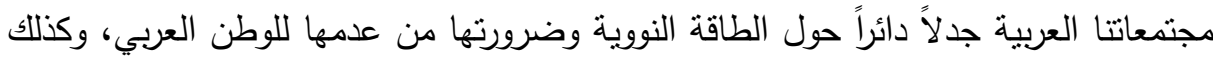

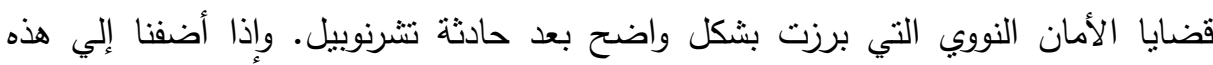

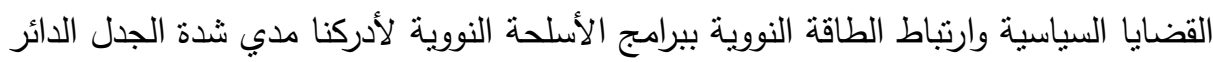

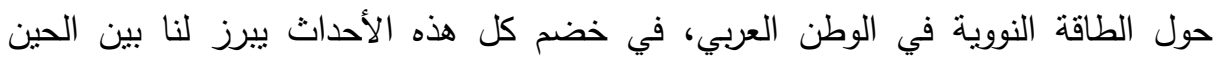

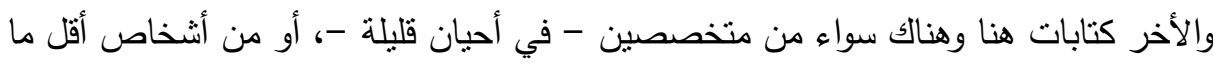
يمكن وصفهم به هو عدم الموضوعية في التناول واستغلال مشاعر الجماهير في أحيان الحيان كثيرة،

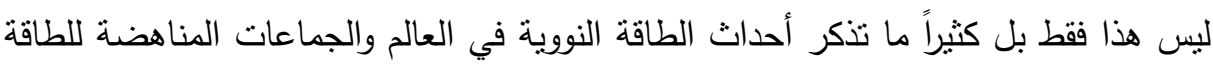

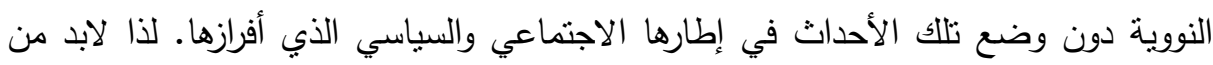

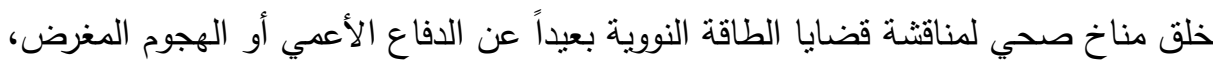

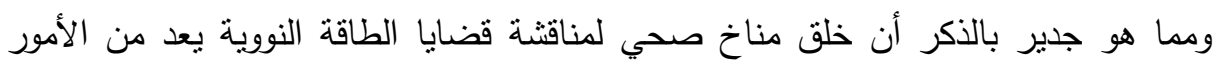

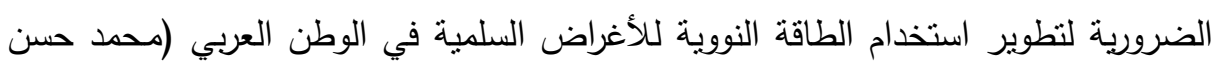

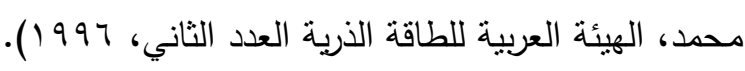

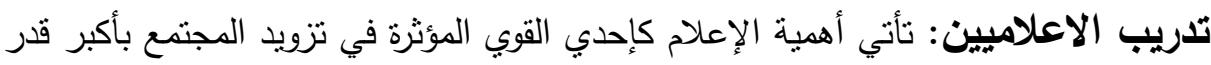

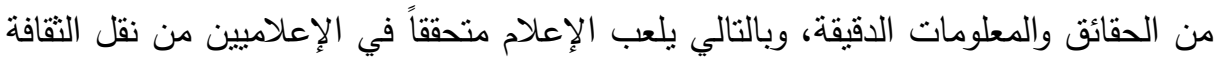
النووية إلي المواطنين لما بستدعي من بناء كوادر إعلامية نووية للمساهمة في توعيتهم.

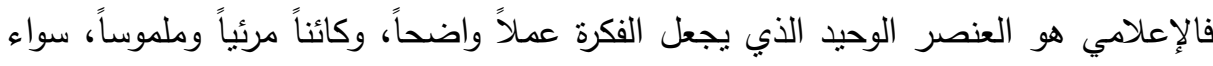

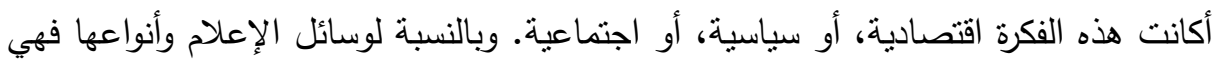


الصحف والمجلات، والمطبوعات والدوريات والملصقات، التليفزيون والراديو ، مواقع الإنترنت،

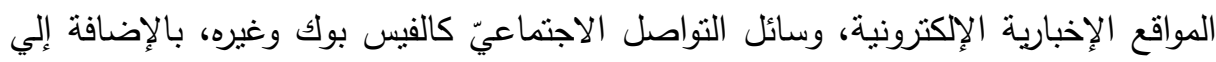

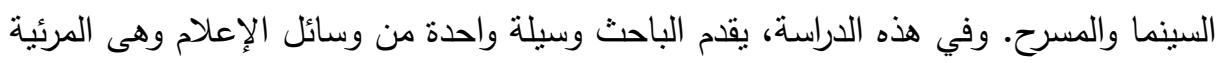
(القنوات الحكومية والخاصة).

الإعلام المصرى يعبر عن التوجه العام للدولة، ونتيجة لذلك فإن الخطط الخاصة به تعتمد على الاستراتيجية العامة للدولة على المستوى الوطنى والقومى والدولى. وتقوم الاسترتيجية العامة للاولة على ثوابت تاريخية وجغرافية نرتبط بمتغيرات سياسية واقتصادية

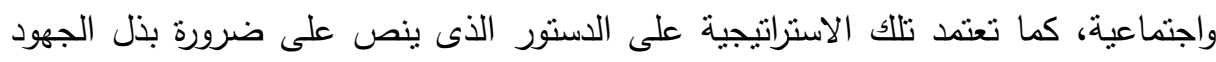
لتحقيق السلام العالمى، المساواه بين المواطنين فى الحقوق والواجبات، حرية الرأى وحرية الصحافة، حرية البحث العلىى والإبداع الأدبى، وبالتالى فإن الإعلام يتحرك بكل العثل أدواته لتحقيق هذه الاستراتيجية. الإعلام المصرى إعلام وطنى جماهيرى تتموى ديموقراطى الإبى حضارى، وبالتالى فإن فلسفة العمل الإعلامى تقوم على عدة منطلقات أهمها تحقيق السيادة

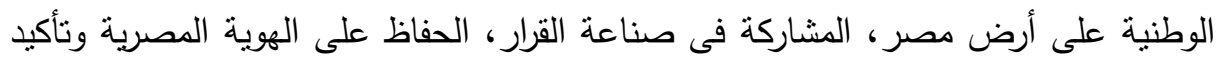

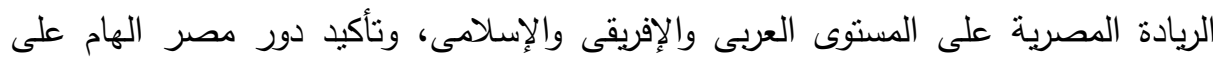
المستوى الدولى. وتتمل كلاً من حرية الرأى، حق الجمهور فى المعرفة، حق وسائل الإعلام فى مأى

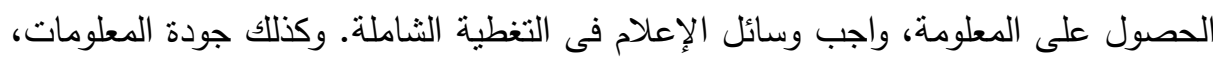

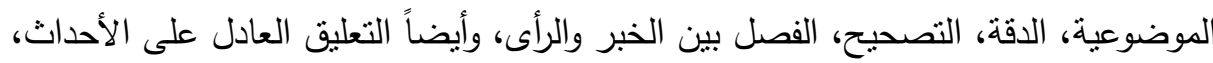
احترام حق كل طرف فى التعبير عن رأيه، عدم التصوير النمطى لأى اتجاه سياسى او فكرى. وأخيراً الدفاع عن مصالح المجتمع وعدم نشرما يسئ للذوق العام. الاستخدام غير السلمي للطاقة الأرية: إن ما أحدثه الاستخدام غير السلمى للطاقة الذرية، والمتمتل فى كم الضحايا التى خلفته القنبلتين يلازم كلمة (الطاقة الذرية) فعلى مدى الذى

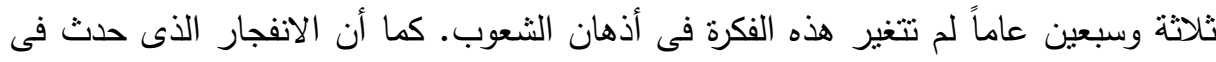

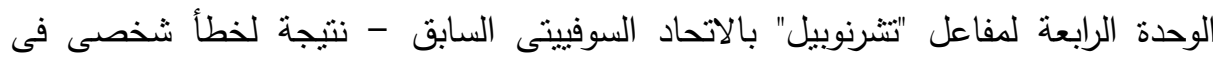

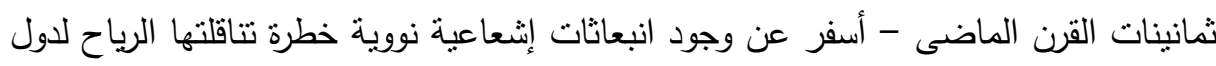


العالم مما أحدث ذعراً للمجتمع العالمى (مجلة أخبار الطاقة الذرية، إبريل 7 ـ ب، ص 1 ا(1)

مع العلم أن الطاقة النووية منلها مثل أى مادة خلقها اله، لها مضارها وفوائدها، ونظراً للتعتيم الإعلامى للهيئات والمنظمات النووية العالمية فإن كثير من الإعلاميين ليس لديهم

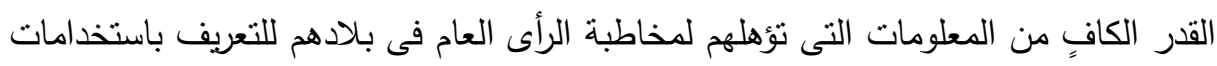

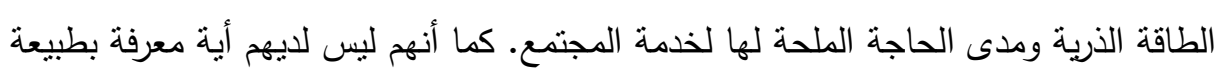
استخدامات الطاقة الذرية وتطبيقاتها فى مختلف مناحى الحياة ومنها المجال الطبي، المجال الصناعي، المجال الزراعي وغيرها من المجالات الأخرى. أهمية استخدام الطاقة الأرية: إن استراتيجية مصر فى مجال النيال استخدامات الطاقة الذرية

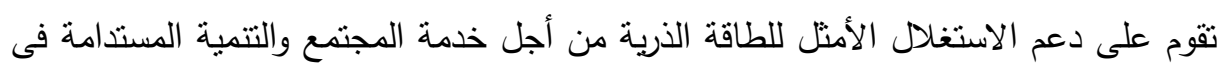

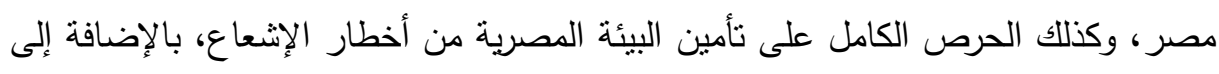

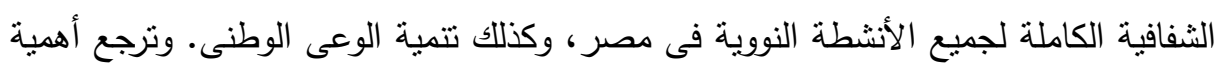

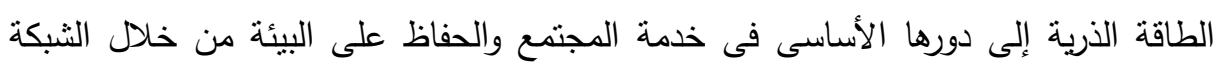

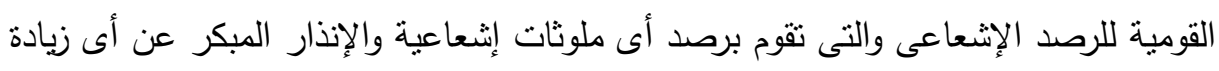

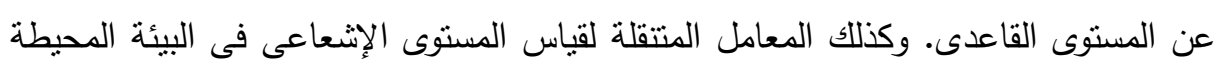

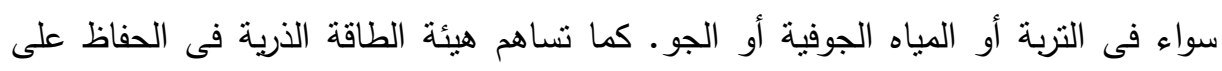

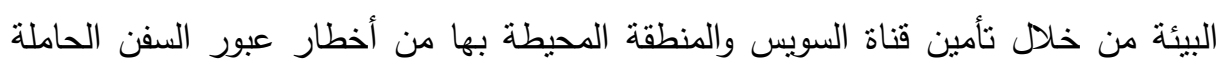

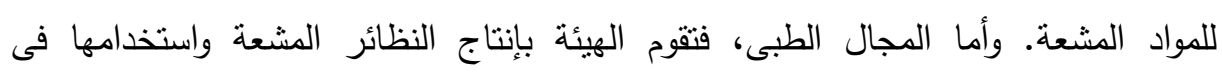
التتخيص والعلاج، وكذلك التحليل بالتقنيات النووية والكثف المبكر عن الأمراض السرطانية

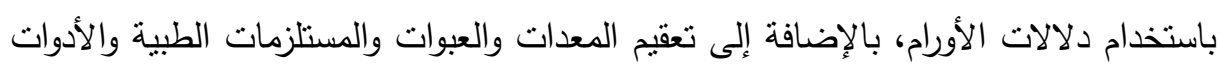

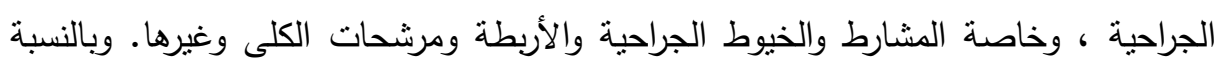

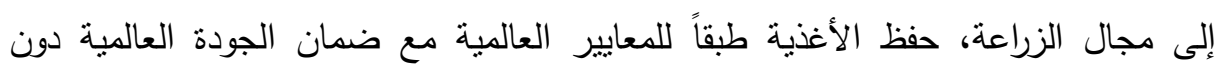
استخدام المبيدات أو المواد الحافظة الضارة مما يؤثز على تقليل نسبة التالف وزيادة فترات 
التخزين، وكذلك استخدام التشعيع الجامى فى استحداث طفرات زراعية جديدة ذات صفات

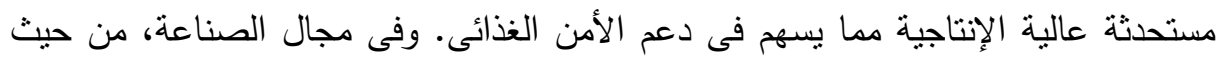

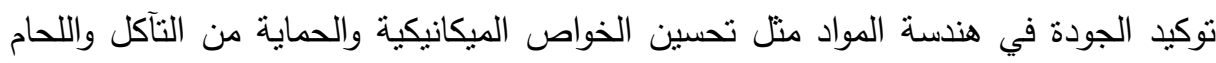
والاختبارات غير الإتلافية. هذا بالإضافة إلى استخدام النظائر المشعة فى قياس إنى إنتاجية آبار البترول ومسامية الصخور والطبقات الحاملة للنفط (كتاب ل.معاماً هيئة الطاقة الذرية،

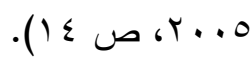

أن الوعي يلعب دوراً هاماً في حياة الإنسان لما يعبر عن مدي فهمه وإدراكه للموضوعات المتتاولة. ويأني بعد ذلك دور المهارة لما نتتاوله الموضوعات والات والأفكار والأخبار من الدقة والسرعة، وفي وقت محدود بما بساعد علي الفهم الجيد والصحيح وذللك من خلال وسائل الإعلام. ومن هنا يأتي دور الإعلامي بما أنه المسئول الوحيد والرئيسي في الوسائل ولئل الإعلامية المرئية، من نقل ونشر الثقافات، وبالأخص الثقافة النووية نتيجة للتعتيم الإعلامي والفقر الثديد في هذه الثقافة النووية. فكان لازاماً علينا من نوضيح مفاهيم الوعي.

\section{إجراعاهت التوراسة}

المنهج المستخدم: استخدمت الدراسة المنهج شبه التجريبي للتعرف علي أثز المتغير المستقل (البرنامج التدريبي) على المتغير التابع (الوعي) واستخدام التصميم شبه التجريبي للمجموعة التجريبية الواحدة ذى التطبيقين (القبلي - البعدي). الأدوات: تتمنل أدوات البحث في الآتي: البرنامج التدريبي: أعد الباحثون تصور مقترح لبرنامج تدريبي للإعلاميين بالقنوات الحكومية

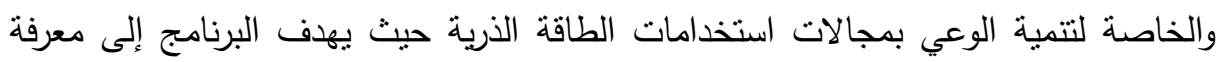
الإعلاميين بالقنوات الحكومية والخاصة بمفاهيم ومصطلحات الطاقة الذرية وكذلك استخداماتها فى المجالات المختلفة منل الطب، الزراعة، الصناعة، ودورها الرئيسى فى خدمة المجتمع المصرى. وكانت الموضوعات المطروحة فى اليوم الأول: التقييم القبلى للبرنامج

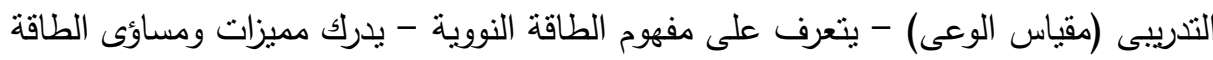


النووية - يستوعب تركيب الذرة والجزئ والمركب - النظائر - يتعرف على ظاهرة التحلل الإشعاعى - فترة عمر النصف - الإشعاعات المؤينة. الوصف العام للبرنامج: وكانت طرق التدريس هى: في اليوم الأول: المناقثة والحوار - المحاضرة - العصف الذهنى - التعليم التعاونى الخطة الزمنية للنطبيق - تجريب البرنامج المحتوي النظري. وفى اليوم الثانى: كانت الموضوعات كالتالى: يتعرف على مفهوم التفاعل النووى والانشطار النووي - إدراك الفرق بين المفاعل النووى والمحطة النورية - يسنوعب معنى الأمن والأمان النووبين. وكانت طرق التدريس: المناقثة والحوار - المحاضرة - العصف الذهنى - التعليم التعاونى. وفى اليوم الثالث كانت الموضوعات كالتالى: مراجعة ما نم تقديمه فى اليومين التدريبيين

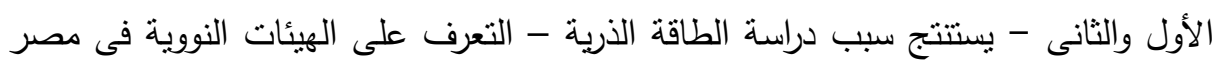
- يمارس المهارات المقدمة فى الإعلام الخاص بالطاقة النووية. وكانت طرق التدريس: المناقثة والحوار - المحاضرة - العصف الذهنى الذهى - التعليم التعاوني. وفى اليوم الرابع كانت الموضوعات كالتالى: مراجعة ماتم تقديمه فى اليوم التدريبى الثالث التعرف على الاستخدامات السلمية للطاقة الذرية. وكانت طرق التدريس: المناقثة والحوار - المحاضرة - العصف الذهنى - لعب الأدوار.

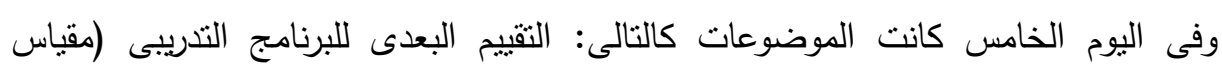
الوعى) - التعرف على المعاهدات والاتفاقيات الدولية والإقليمية لحظر أسلحة الدمار الثامل - مراجعة المحتوى التدربيى خلال الأيام الأربعة السابقة.

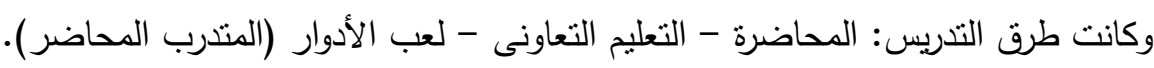

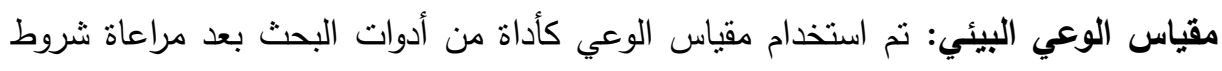

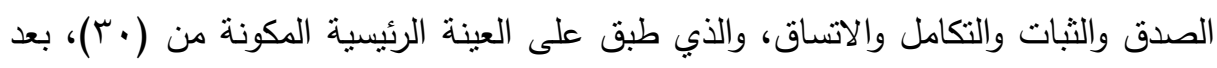

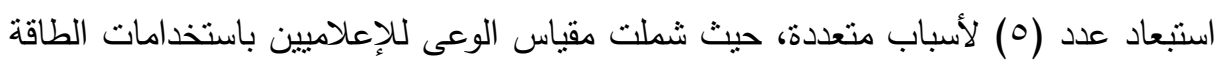
الذرية، وتتضمن تقييم مستوي الإعلاميين قبل وبعد نطبيق البرنامج التدريبي. وبعد جمع القوائم

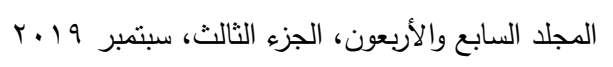


ومراجعتها، واستبعاد غير الصالحة منها قام الباحثون بإدخال البيانات الحاسب الآلي، وقد استعان الباحث بالأساليب الإحصائية المختلفة. الوصف العام للمقياس: مقياس الدراسة بعنوان: برنامج تدريبى للإعلاميين بالقنوات الحكومية والخاصة لتتمية الوعى بمجالات استخدامات الطاقة الذرية ومهارات تتاولها. يتم تطبيق البحث قبل وبعد تقديم البرنامج التدريبي بهدف تقييم مستوي المعارف

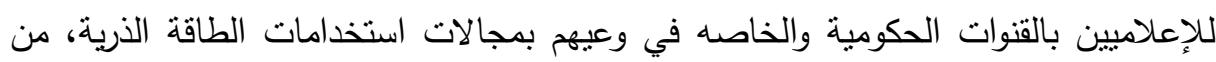
خلال استخدام عدد (T ا ( ) عبارة لبعد (وعي الإعلاميين).

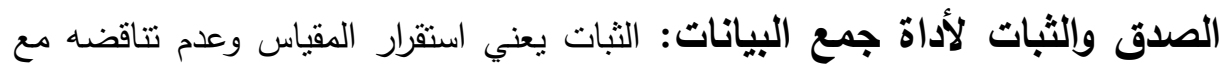

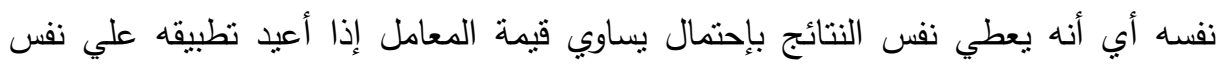
العينة. أما الصدق فيقصد به أن المقياس يقيس ما وضع لقئ لقياسيه.

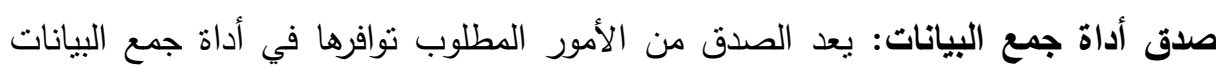

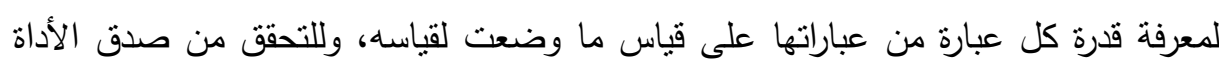

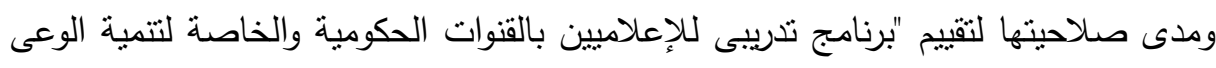

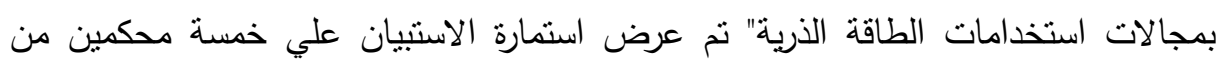
أعضاء هيئة تدريس الجامعات المصرية من ذوي الإختصاص، ووفقات لتوجيهاتهم تم تعديل قائمة الاستبيان لتصبح في صيغتها النهائية ثلاثة أقسام رئيسية. ثبات أداة جمع البيانات: هناك العديد من الطرق لحساب ثبات أداة جمع البيانات منها طريقة ألفا كرونباخ، طريقة إعادة تطبيق الإختبار وفي هذه الدراسة ينم إستخدام طريقة ألفا كرونباخ لحساب درجة الثبات بإستخدام معامل م وفقا للمعادلة التالية:

$$
\begin{array}{r}
\alpha=\frac{k}{k-1}\left[1-\frac{\sum s_{i}^{2}}{s_{t}^{n}}\right] \\
\text { حيث } 2 \\
\text { عدد مفردات (فقرات) الاختبار. }
\end{array}
$$

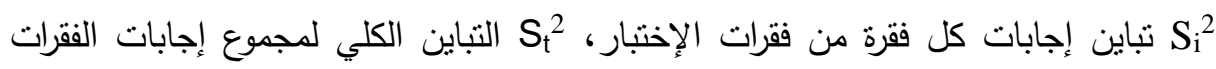
للإختبار • 
وبتطبيق هذه المعادلة علي إجابات للإعلاميين بالقنوات الحكومية والخاصة ظهر أن

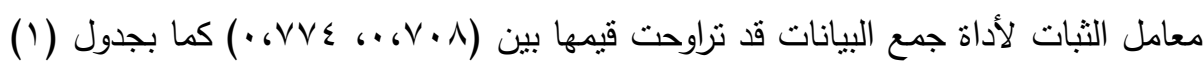

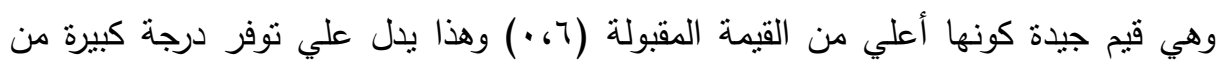

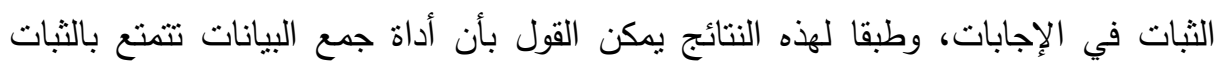
الداخلي لعباراتها وانها تفي بأغراض الدراسة وزيادة قيمة معامل ألفا كرونباخ يعني زيادة

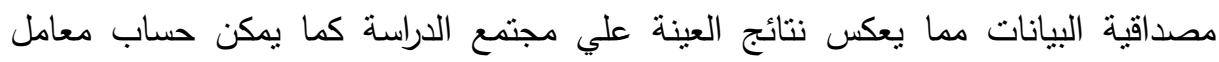
الصدق الظاهري بحساب جذر معامل الثبات.

جدول (1): الصدق والثبات لأسئلة قائمة استنبان للإعلاميين بالقنوات الحكومية والخاصة

\begin{tabular}{|c|c|c|c|c|}
\hline الصدق الظاهري & الثبات & عدد الفقرات & \multicolumn{2}{|c|}{ متغيرات الدراسة } \\
\hline$\cdot, \wedge \wedge$. & $\cdot, \vee \vee \vee \leqslant$ & 7 & المنهج & \multirow{4}{*}{ تدريب البعاد المتغير المستقل } \\
\hline$\cdot, 101$ & $\cdot, Y Y O$ & 0 & المدربين & \\
\hline$\cdot, \wedge \leqslant 1$ & $\cdot, V \cdot \Lambda$ & 0 & الأدوات المساعدة & \\
\hline$\cdot, \wedge \circ \mathrm{V}$ & • & 17 & الإجمالي & \\
\hline$\cdot, \wedge \vee 0$ & $\cdot, \vee \vee 0$ & 1r & وعي الإعلاميين & \multirow{2}{*}{ كفاءة الإعلادميين التغير التابع } \\
\hline$\cdot, \wedge \vee q$ & $\cdot, V \vee Y$ & Ir & الإجمالي & \\
\hline
\end{tabular}

عينة الاراسة: شملت عينة البحث (•r) إعلامياً من مجموعة الإعلاميين بنظام الفريق،

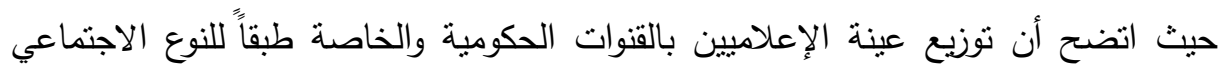

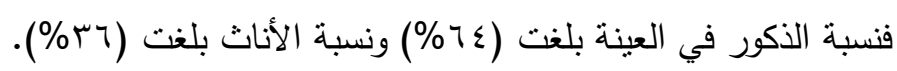

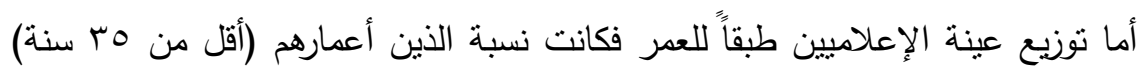

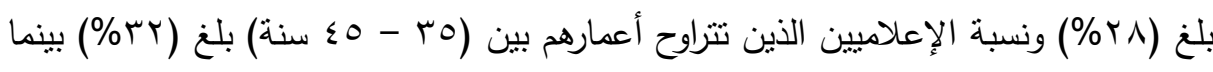

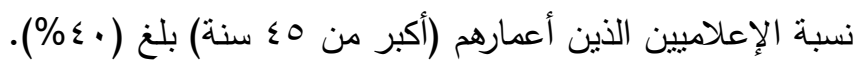

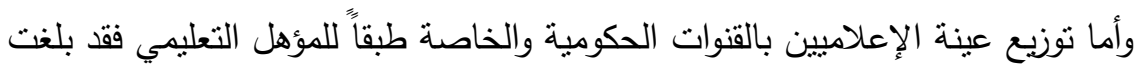

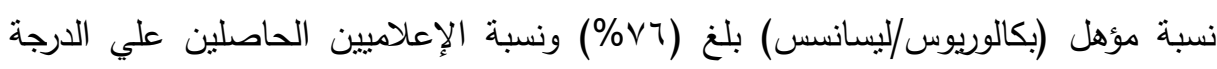

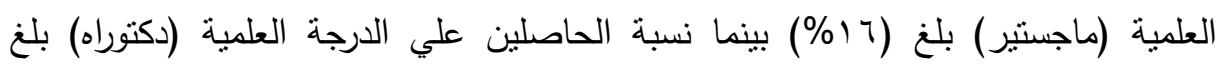


في حين كان توزيع عينة الإعلاميين بالقنوات الحكومية والخاصة طبقاً لسنوات الخبرة

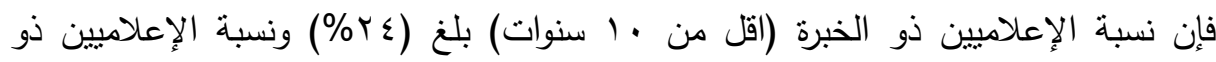

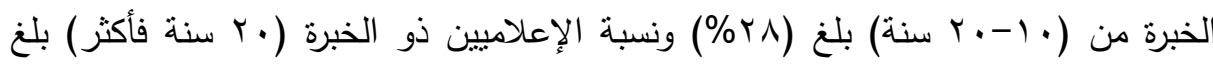
. (\%乞^)

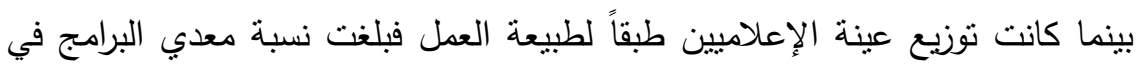

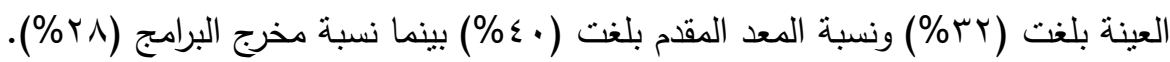

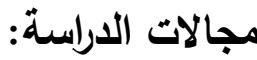

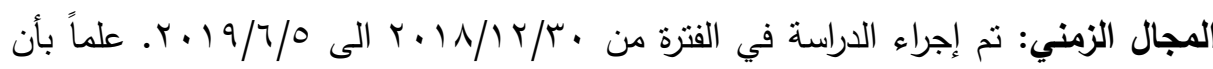

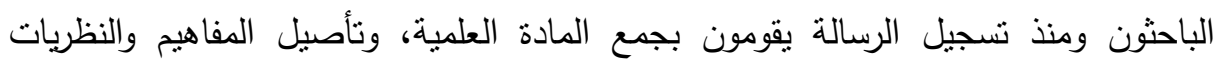
والدراسات المرتبطة بموضوع الدراسة، وهى فترة جمع الإطار النظري للاراسة حتى تقوم على التى

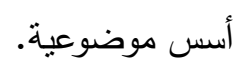
المجال المكاني: مجموعة من القنوات الحكومية والخاصة. الأساليب الإحصائية المستخدمة:

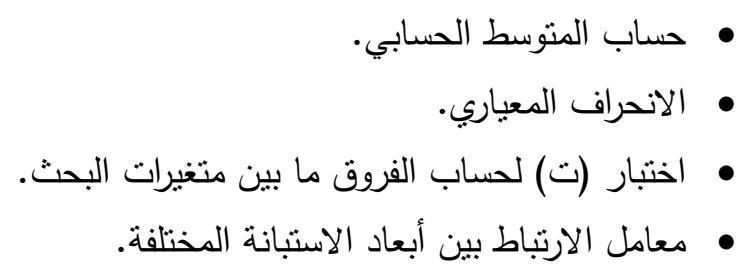

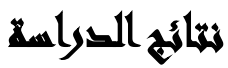

تناول هذا البحث دور البرنامج التنريبي للإعلاميين بالقتوات الحكومية والخاصة لتتمية

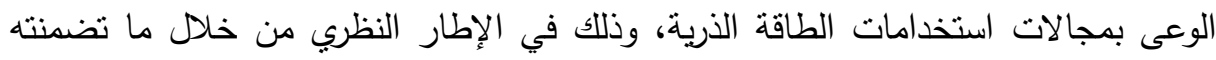

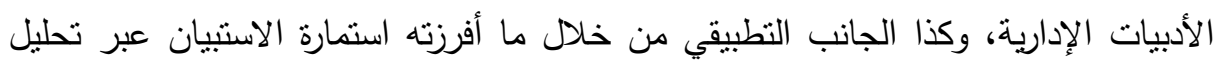

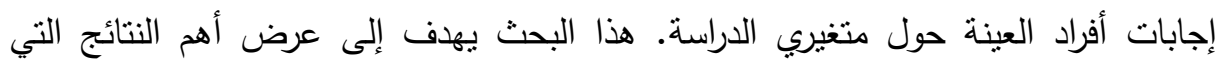

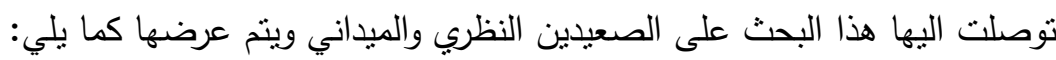


جدول (r): التقييم القبلي والبعدي للاعلاميين بالقنوات الحكومية والخاصة للمتغير التابع

\begin{tabular}{|c|c|c|c|c|c|c|}
\hline \multicolumn{7}{|c|}{ وبعديه } \\
\hline \multicolumn{3}{|c|}{ التقيم البعدي } & \multicolumn{3}{|c|}{ التقييم القبلي } & المتغير \\
\hline الفجوات & الانحراف & الحستوسطي & نسبة الفجوات & الانحراف & الحسابي & وبعدية \\
\hline$\%) \cdot, r \cdot-$ & $\cdot, I T V$ & $\varepsilon, 010$ & $\% r v, \varepsilon q$ & $\cdot, r 0 \leq$ & r, Iro & الإعلاميين \\
\hline$\% 9,0 \leq-$ & $\cdot, 1 \cdot 1$ & $\varepsilon, \varepsilon \vee V$ & $\% r \vee, \wedge \uparrow$ & $\cdot, r 10$ & $r, 1 \cdot V$ & الإعلاميين \\
\hline
\end{tabular}

جدول (Y) يبين مقارنة بين الثقييم القبلي والبعدي للإعلاميين بالقنوات الحكومية والخاصة للمتغير التابع (أداء الإعلاميين) وبعده (وعي الإعلاميين) ويتضح من الجدول

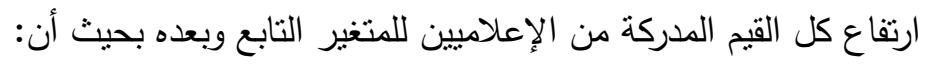

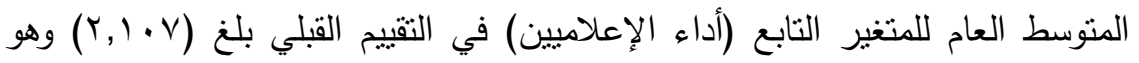

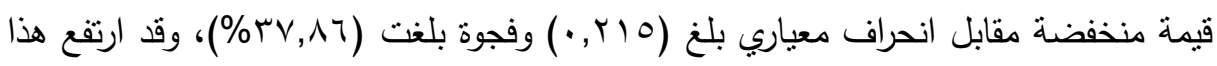

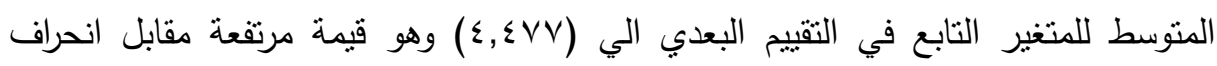
معياري بلغ (1 • (. •) ولا نوجد فجوات، وبالمتل ارتفعت متوسطات بعده (وعي الإعلاميين) بعد تطبيق برنامج التدريب النووي كما يلي: المتوسط العام للبعد الأول (وعي الإعلاميين) للمتغير التابع (أداء الإعلاميين) في

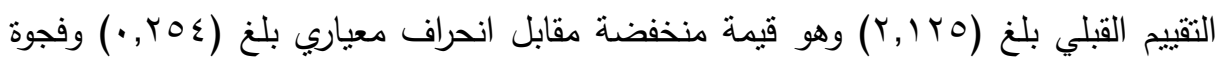

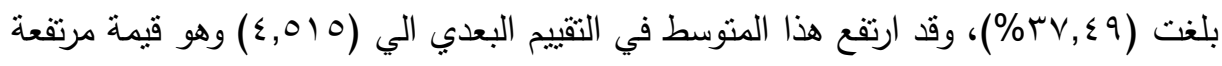

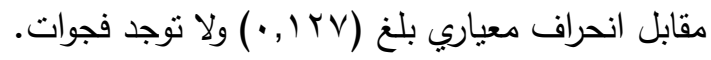

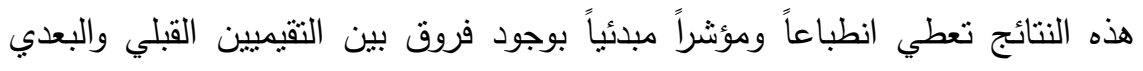

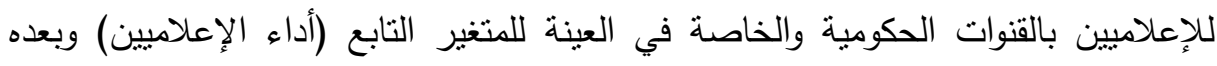
(وعي الإعلاميين) لصالح التقييم البعدي بعد تطبيق برنامج التدريب النووي. 
تفسير النتائج: توصل البحث إلي مجموعة من النتائج والتي أجابت بدورها عن النساؤلات

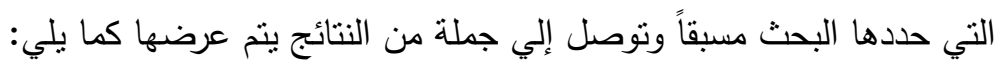

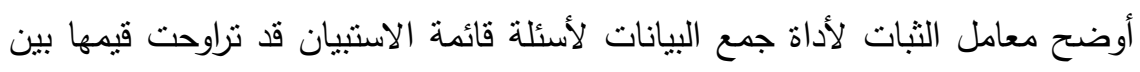

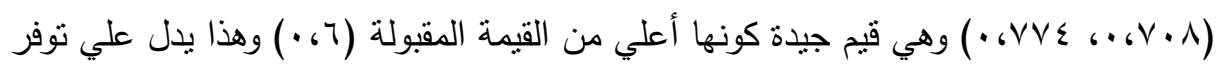
درجة كبيرة من الثبات في الإجابات.

وبداية تبين انخفاض المستوي المدرك من الإعلاميين بالقنوات الحكومية والخاصه في الإسي

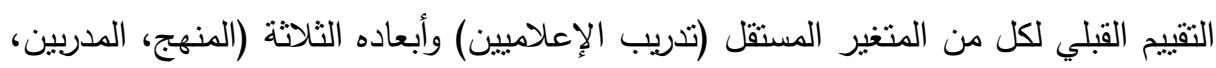
الأدوات المساعدة). كما ظهر انخفاض المستوي المدرك من الإعلاميين بالقنوات الحكومية والخاص في التقييم القبلي لكل من المتغير التابع (مستوي أداء الإعلاميين) وبعده (وعي الإعلاميين).

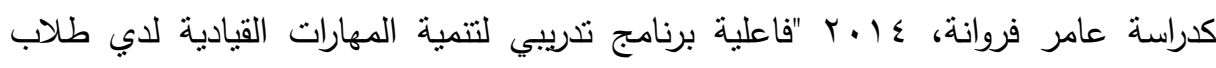

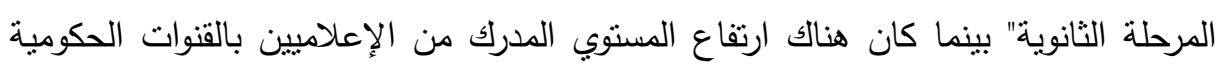
والخاص في التقييم البعدي لكل من المتغير المسنقل (تدريب الإعلاميين) وأبعاده الثلاثة

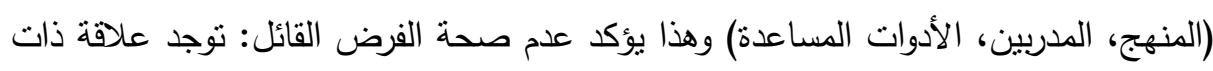
دلالة احصائية بين البرنامج التدريبى (بعده الأول المنهج) ومسنوي أداء الإعلاميين (ببعده الادواه

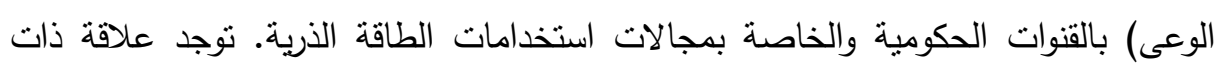
احصائية بين البرنامج التدريبى (بعده الثانى المدربين) ومستوي أداء الإعلاميين (ببعده الوعى)

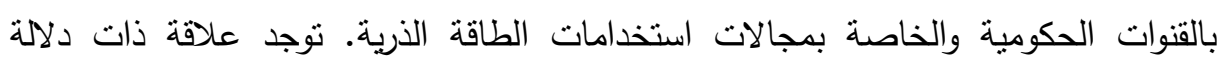
احصائية بين البرنامج التذريبى (بعده الثالث الأدوات المساعدة) ومستوي أداء الإعلاميين (ببعده الوعى) بالقنوات الحكومية والخاصة بمجالات استخدامات الطاقة الذرية.

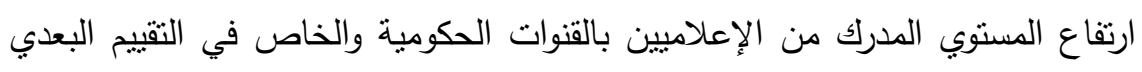

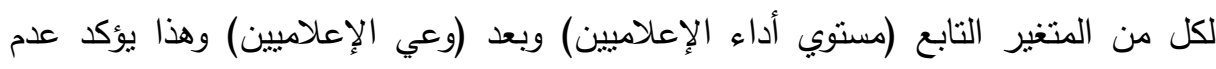

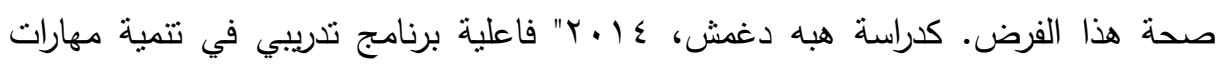
تصميم وإنتاج ملف الإنجاز الإلكتروني والاتجاه نحوه لاي طالبات كلية التربية بالجامعة الإسلامية بغزة. 
تطبيق البرنامج التنريبى علي مجالات استخدامات الطاقة الذرية للإعلاميين (المعد

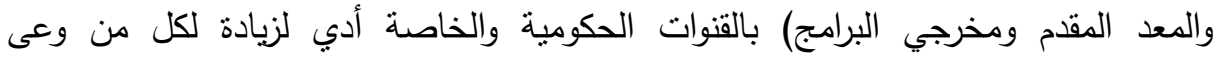
الإعلاميين لهذه المجالات وقد تنين ذلك من خلال:

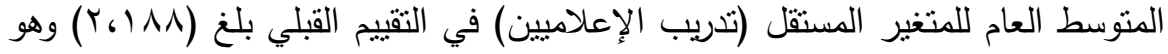

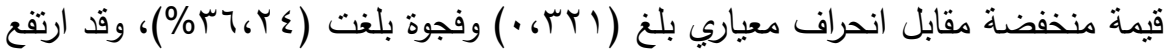

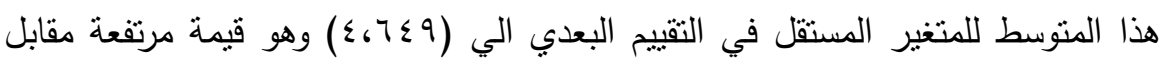
انحراف معياري بلغ (•7 (، •) ولا توجد فجوات، وبالمتل ارتفعت متوسطات أبعاده الثناثة (المنهج، المدربين، الأدوات المساعدة) بعد تطبيق برنامج التنريب النووي. وتم تأكيد معنوية هذه الفروق بمجتمع البحث بتتفيذ عدد (ع) اختبارات (2 sample T) بين منوسط إجابات (إدراك) الإعلاميين للتقييم القبلي والبعدي للمتغير المستقل وأبعاده

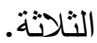

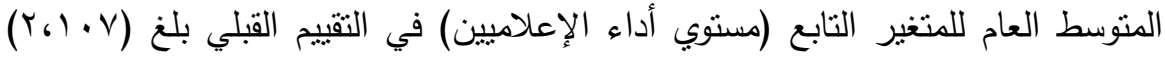

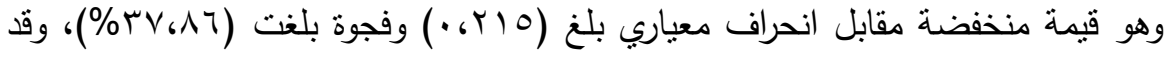

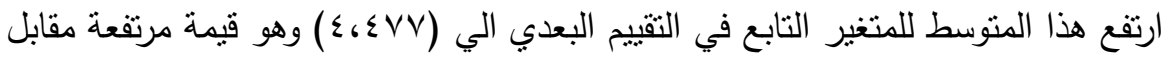

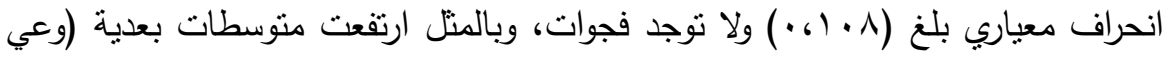
الإعلاميين) بعد نطبيق برنامج التدريب النووي. (2 sample T) ونتم تأكيد معنوية هذه الفروق بمجتمع البحث بتتفيذ عدد (r) اختبارات بين منوسط إجابات (إدراك) الإعلاميين للتقييم القبلي والبعدي للمتغير التابع.

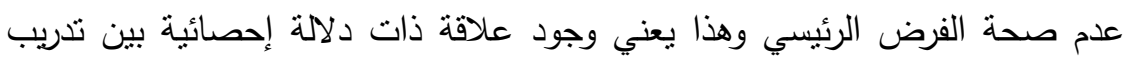
الإعلاميين بالقنوات الحكومية والخاصة على مجالات استخدامات الطاقة الذرية وزيادة مستوي أدائهم. والذي تم من خلال: نتائج اختبار العلاقة بين تدريب الإعلاميين بالقنوات الحكومية والخاصة وزيادة مستوي أدائهم بهذه القنوات أثنتت وجود علاقة لثنة معنوية ايجابية. 
- تم التأكيد علي عدم صحة الفرض الرئيسي بإثبات عدم صحة الفرضين الفرعيين له ويعني وجود علاقة ذات دلالة إحصائية بين تدريب الإعلاميين بالقنوات الحكومية

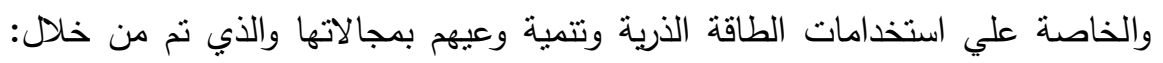
نتائج اختبار العلاقة بين البعدين (وعي الإعلاميين) للمتغير التابع (أداء الإعلاميين)

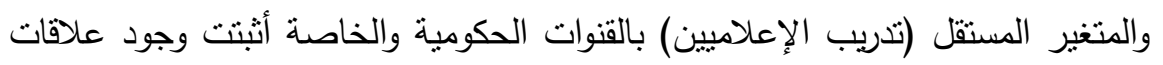
معنوية ايجابية. كدراسة (2012) Kaya " تقصي مدي ممارسة معلمي الجغرافيا في

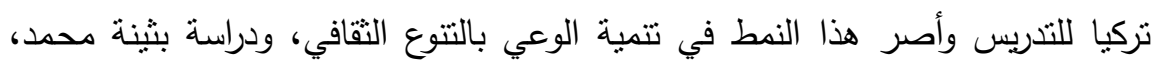

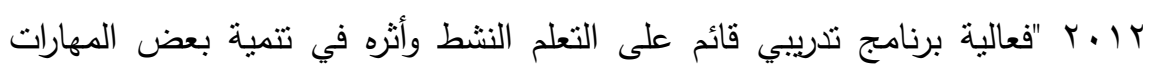
اللغوية لدي طالبات الصف الأول المتوسط بالسعودية.

\section{المجروياهت}

يوصي البحث بمجموعة من التوصيات أهمها:

الإهتمام بتدريب الإعلاميين بمجالات استخدامات الطاقة الذرية، والتي نأكدت أهميتها في لهي حباتتا اليومية. أهمية مشاركة الإعلاميين في المؤتمرات الخاصة بمجالات استخدامات الطاقة الذرية علي المستويين الوطني والعالمي. تبسيط ونشر ثقافة العلوم النووية لدى الإعلاميين وطرحها عبر وسائل الإعلام المختلفة لتصل إلى المواطن المصرى والعربى للحد من المفاهيم الخاطئة للطاقة الذرية.

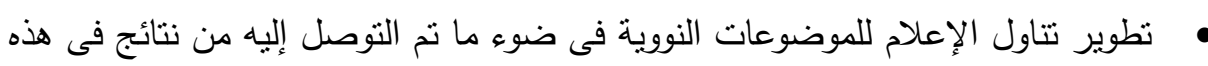
الدراسة، وايضاح كيفية التعامل عند حدوث طارئ نووى من أى مصدر مستخدم، ولتكوين رأي عام مساند للقضايا النووية من خلال عقد ندوات.

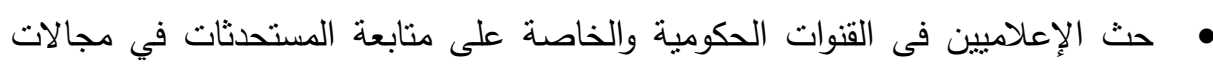
الطاقة الذرية من خلال إعداد زيارات للإعلاميين لمواقع الهيئات النووية والتعرف على على لفئه كل ما يقدمونه على أرض الواقع. 
إنشاء قاعدة بيانات ومعلومات تحتوي على كتب ومراجع موتقة عن الطاقة النووية واستخداماتها تمكن الإعلاميين بالقنوات الحكومية والخاصة الرجوع إليها والاستفادة من محتواها العلمي في إنتاج برامجهم المنتوعة.

إنتاج أفلام وثائقية عن الهيئات النووية وعرضها من خلال القنوات الحكومية والخاصة. مراعاة التكامل بين الإعلاميين وخبراء الطاقة الذرية في إنتاج برامج الإعلاميين الخاصة

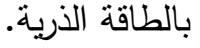

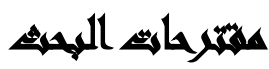

فى ضوء ما تم التوصل إليه من نتائج توصي البحث بإجراء الدراسات التالية:

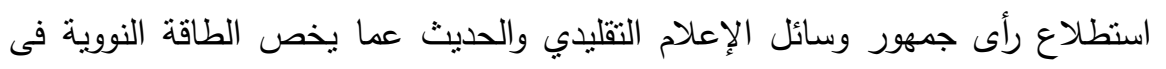
القنوات الحكومية والخاصة. التعرف علي المضامين المختلفة وأساليب الإقناع التي بمكن استخدامها في مجالات الطاقة الذرية. تقوم هيئة الطاقة الذرية بتوقيع بروتوكول تعاون بينها وبين الهيئة الوطنية للإعلام من خلاله ينت تدريب الإعلاميين في التليفزيون المصري قبل العمل في مجال الطاقة الذرية.

\section{zall}

أحمد عريقات، دور التلبفزيون الأردني في نوعية الثباب أثناء الإنتخابات البرلمانية عام

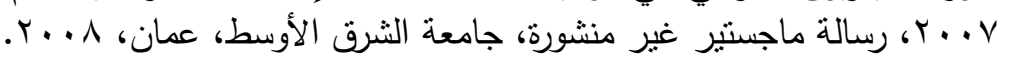

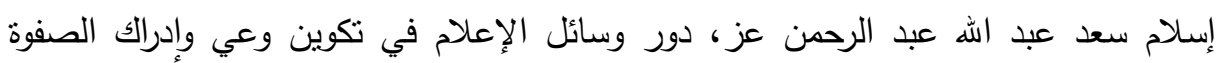

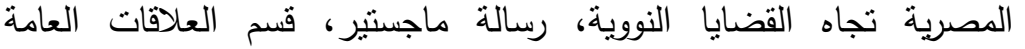

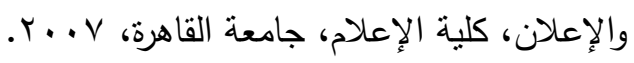


بثينة محمود محمد، فعالية برنامج تدريبي قائم علي التعلم النشط في الأداء التدريسي للطالبات

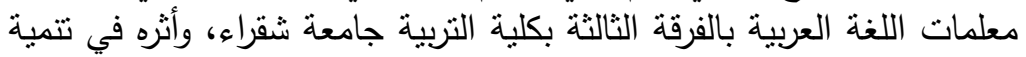

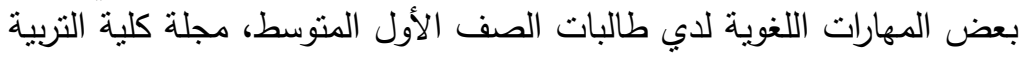

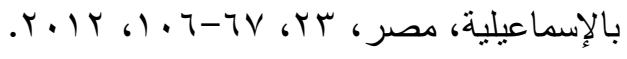

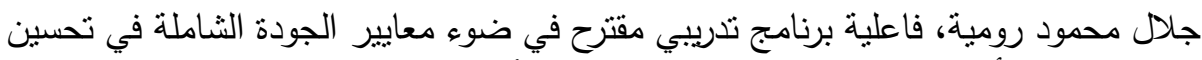

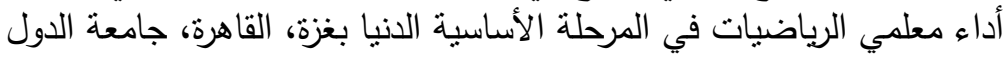

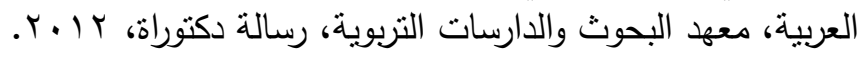

طلعت عيسى، فاعلية استخدام وسائل الإعلام الجديد في نجاح فعاليات إنهاء الانقسام

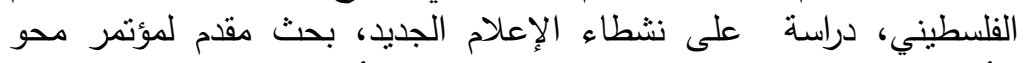

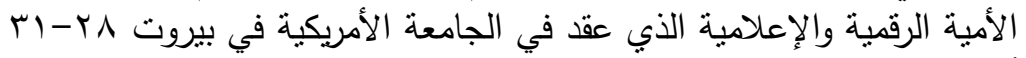

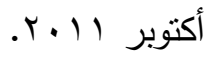

عامر محمد عبد فروانة، فاعلية برنامج تدريبي لتنمية المهارات القيادية لاي طلاب المرحلة

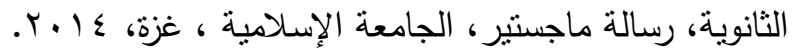

عبد الرحيم درويش، واقع إستخدام الجمهور المصري واتجاهاته نحو التلافزيون، دراسات في

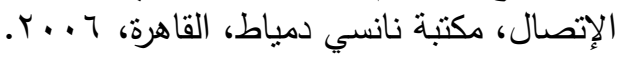

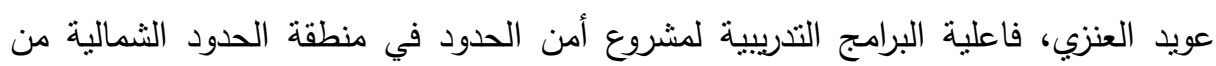

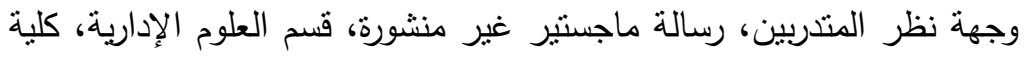

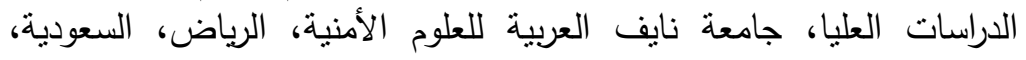

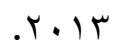

هبه دغمش، فاعلية برنامج تدريبي في تتمية مهارات تصميم وإنتاج ملف الإنجاز الإلكتروني

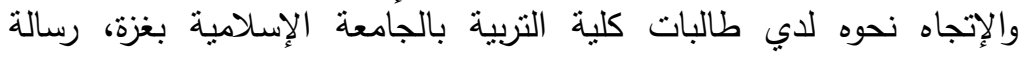

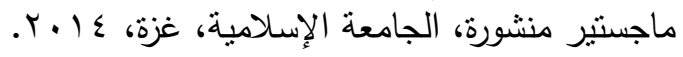

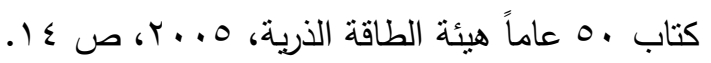

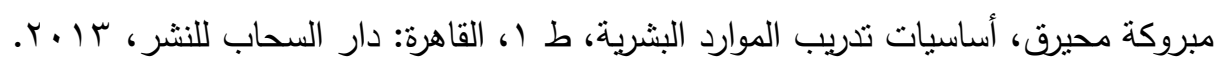

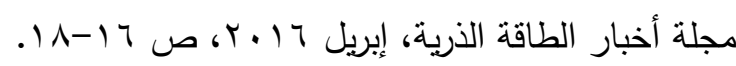

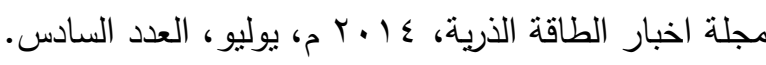

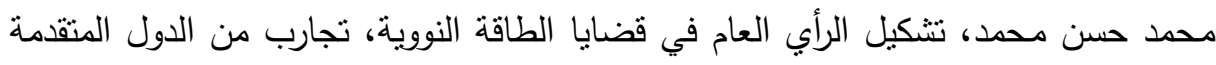

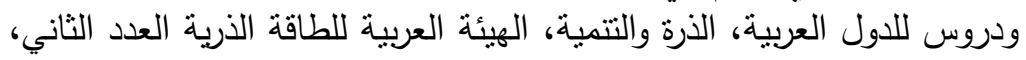


محمد معوض إبراهيم، دراسات إعلامية، الجزء الثاني، دار العلم للنشر والتوزيع، مصر، . Y. . ¿

محمد منير حجاب، الموسوعة الإعلامية، القاهرة، مكتبة دار الفجر للنشر والتوزيع، المجلد

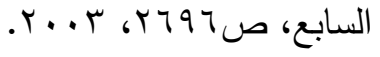

Al-Mzary, M. \& Al-rifai, A. \& Al-Momany, M.: Training and its Impact on the Performance of Employees at Jordanian Universities from the Perspective of Employees: The case of Yarmouk University, Journal of Education and Practice. $6(32), 2015$.

Kaya, Erdogan, A case study on constructivist Geography teaching based upon folk culture, E-Journal of New World Sciences Academy (NWSA), vol.7, no.1, p.79-98, 2012. 
طارق عبد العزيز وآخرون

\title{
A TRAINING PROGRAM FOR MEDIA MEN IN GOVERNMENTAL AND PRIVATE CHANNELS FOR \\ DEVELOPING AWARENESS OF THE FIELDS \\ OF ATOMIC ENERGY USES \\ AND ITS CIRCULATION SKILLS
}

Tarek A. Farag ${ }^{(1)}$; Mohamed M. Ibrahim ${ }^{(2)}$;

Abdel Hakeem El-Manhawy ${ }^{(3)}$ and Samah I. Torab ${ }^{(1)}$

1) Nuclear Research Center, Atomic Energy Authority 2) Faculty of Childhood Studies, Ain Shams University 3) Faculty of Technical Military

\begin{abstract}
The study aims at training the media men of the terrestrial channels including the first channel - the Delta channel - the Nile cultural channel - the Nile news channel - the Alexandria channel - the Upper Egypt channel and the private satellite channels such as Dream - CBC Life - Sada El-Balad - Al-Kahira Wa Al-Naas (Cairo and the people) through the application of a training program about the use of atomic energy and circulation skills to address, during the analysis of the time period in 2018; through the design of the a questionnaire form and a sample of (30) media men range between the author, the presenter, the director and the photographer.

Regarding the study method, it uses the semi-experimental approach. The study significance is reflected in educating the public about nuclear culture in addition to the identification of how to deal with nuclear energy in case of occurring a nuclear or radiant disaster and move this awareness to the street man to absorb it. The study hypothesis is embodied in that "There is no statistically significant relationship between the (method) in the training program and the efficiency of the media in the terrestrial and private terrestrial channels in the fields of the use of atomic energy".
\end{abstract}

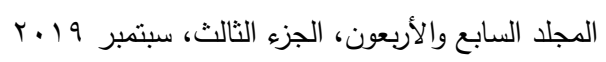




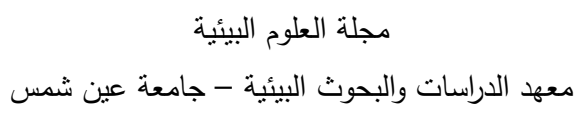

The researcher uses the questionnaire form, which is prepared in the form of 25 forms, using the pre/post application of the training program. The questionnaire includes several sections related to the personal and occupational and functional aspects of the media men, their training and the efficiency of their performance.

The SPSS statistical program is used for compiling and entering the questionnaires data to test the validity, reliability and credibility of the data collection tool by measuring the reliability coefficient, the descriptive analysis of the demographic characteristics, and the calculation of the general mean of the independent variables as well as their dimensions. The results show and prove validity of the hypotheses.

The study results come to that: Percentage of media professionals with experience (less than 10 years) has reached (24\%) and the proportion of media professionals with experience of (10-20 years) has reached $28 \%$ and the proportion of media professionals with experience (20 years and above) reached (48\%).

The study recommends the necessity to prepare specialized media cadres in the nuclear field through media participation in nuclear scientific conferences. 